\title{
Introduction to the Special Issue on $\mathrm{HCl}$ and the Body: Reimagining Women's Health
}

\author{
TERESA ALMEIDA*, IT University of Copenhagen \\ MADELINE BALAAM, KTH Royal Institute of Technology \\ SHAOWEN BARDZELL, Indiana University \\ LONE KOEFOED HANSEN, Aarhus University
}

CCS Concepts: • Human-centered computing $\rightarrow$ HCI theory, concepts and models; Interaction design theory, concepts and paradigms;

Additional Key Words and Phrases: Women's health, bodies, feminism, activism, emancipatory politics

\section{ACM Reference format:}

Teresa Almeida, Madeline Balaam, Shaowen Bardzell, and Lone Koefoed Hansen. 2020. Introduction to the Special Issue on HCI and the Body: Reimagining Women's Health. ACM Trans. Comput.-Hum. Interact. 27, 4, Article 20 (August 2020), 32 pages.

https://doi.org/10.1145/3406091

\section{AN INTRODUCTION BY OUR SELVES}

In the fields of human-computer interaction (HCI) and interaction design, there has been an increasing exploration of technology in relation to the body and in particular around issues associated with "women's health." Much of the work so far has been about ways design and technology can play in supporting transitions to and experiences of motherhood and maternal health, menstruation, domestic violence, abortion, pregnancy loss, intimate anatomical awareness, fertility management, continence care, menopause, voice training for trans-women, gender stereotypes in voice assistants, and reimagining existing practices and technologies, among others. This Special Issue has been put together to bring together various voices and research strands from within this emerging community of researchers in order to discuss the core ideas, approaches, issues, and challenges that are currently pressing for this area of research.

This ToCHI Special Issue is the product of two-and-a-half years of labour from the original proposal up to the final collection of articles you see before you now. It has involved multiple

\footnotetext{
*The four editors contributed equally to the curation of this special issue.

Authors' addresses: T. Almeida, IT University of Copenhagen, Rued Langgaards Vej 7, DK-2300 Copenhagen S, Denmark; email: teal@itu.dk; M. Balaam, KTH Royal Institute of Technology, Lindstedtsvägen 3-5, SE-10044 Stockholm, Sweden; email: balaam@kth.se; S. Bardzell, Indiana University, 901 E. Tenth Street, Bloomington, IN 47408; email: selu@indiana.edu; L. K. Hansen, Aarhus University, Langelandsgade 139, DK-8000 Aarhus C, Denmark; email: koefoed@cavi.au.dk.

Authors' current addresses: T. Almeida, Umeå University, MIT-huset, Campustorget 5, 90187 Umeå, Sweden; email: teresa.almeida@umu.se; S. Bardzell, Pennsylvania State University, E361 Westgate Building, University Park, PA 16802; email: sbardzell@psu.edu.

Permission to make digital or hard copies of all or part of this work for personal or classroom use is granted without fee provided that copies are not made or distributed for profit or commercial advantage and that copies bear this notice and the full citation on the first page. Copyrights for components of this work owned by others than ACM must be honored. Abstracting with credit is permitted. To copy otherwise, or republish, to post on servers or to redistribute to lists, requires prior specific permission and/or a fee. Request permissions from permissions@acm.org. (C) 2020 Association for Computing Machinery.

1073-0516/2020/08-ART20 \$15.00

https://doi.org/10.1145/3406091
} 
conversations between the editors and between the authors and editors. Inspired by Data Feminism [36] and many feminist scholars before that, we wish to hold ourselves to account in terms of the values that we as guest editors of ToCHI share, and the extent to which we have been able to uphold ourselves to these values. In curating this Special Issue, we hoped to explore women's health HCI issues at a global scale. We aimed at highlighting new technologies and new interactions that might respond to core issues affecting women's health, as well as critically engaging with the sociopolitical context that contributes to health inequality for women and girls worldwide. We wished to generate a pluralistic and intersectional account of women's health and HCI, one that would speak to issues of race, sexuality, poverty, disability, and aging.

In our Call for Papers, we requested potential authors to submit a short abstract of their planned paper, so we could gauge the broader interest in the topic and the variety of issues being addressed. We were overwhelmed by the response, and indeed many interesting topics were raised, and it was very difficult to decide on a manageable number that we would invite to proceed with the development of a full manuscript for review. Among the abstracts we received, we invited 16 groups of authors to submit full-length papers, and eventually we accepted seven papers for this Special Issue, all having been through three rounds of rigorous peer-reviewing process. Our reviewers included both junior and senior scholars, with expertise in HCI, health, feminism, gender, design, Cultural Studies, and Science and Technology Studies (STS).

Looking at the submissions received for the Special Issue, there were surprisingly few works on how gender, racism, ageing, poverty, ableism, obesity, rurality, mental wellness, HIV, and cancer intersect with women's health, as well as work from/about regions such as Africa or South and Central America, or the Middle East. And those that did unfortunately did not make it beyond the peer-reviewing process, despite our efforts to encourage them throughout the process. The lack of such contributions or their rejection during the peer-reviewing process was a disappointment. We were also expecting more contributions from the mainstream health informatics community, but we did not have many, and those we had did not emerge successfully from the reviewing process. Additionally, we were hoping to receive contributions around emergent technologies and women's health, but we did not receive any submissions of that nature either. None of this should be seen as a failing of our field, nor the researchers, but instead highlighting the possible gaps that exist within the current research in this area as a way of motivating all of us interested in this topic. We believe that some of the gaps are the result of systemic issues within academia that make some voices harder to be heard. Some of these are on us too: Did we get the call out wide enough? Are we in the right networks?. We have taken note of how we might do better in the future, because the diversity in research is on all of us to improve. In spite of these limitations, we remain hopeful in that there is much to be explored in/about women's health and the body in HCI. Moving forward, we hope to see more work in this space that goes beyond the limited geographical regions, stands in contrast to the existing politics around women's health, and creates new ways of relating to our bodies in/with/through technologies. Such a more expansive view opens up many new and exciting possibilities. The collection of papers in this Special Issue represents only the beginning of the effort towards this end. They not only introduce new practices into women's health HCI but also suggest new kinds of hope.

Traditionally, a special issue begins with an introduction written by the special issue editors where together the editors narrate the motivation and purpose of the special issue through a single, authoritative voice. A key goal of such a piece is to highlight the main contributions of the articles selected to be published with the special issue, and where possible put those contributions into conversation with one another to showcase the current research landscape-what is well charted, and where needs more work, what are the key concerns, and where are the boundaries. 
We have chosen to do something a little different. Instead, what we offer here is a series of conversations between the four editors. The process of talking, responding, and reflecting is simultaneously an individual and collective task, and we see the form of conversations as our feminist commitment to challenge the dominant epistemology, research methodology, and politics in doing women's health research in the field with the hope of creating some new openings. We wish to make visible that this area of research is still very much open, and its boundaries are blurred. There is no one established way to proceed and no agreed methodology for undertaking research in this area. We, as editors of this Special Issue, while all actively researching women's health HCI, do not have all the answers. In what follows, we share our conversations around four themes about women's health research that we came back to time and time again as we curated this Special Issue and show how we and these authors walk alongside each other.

\section{TOWARDS A NEW FEMINIST HEALTH POLITICS IN HCI}

Madeline. Clearly, maternal health is a significant area within women's health concerns. According to the World Health Organization, 1,000 women die everyday due to the consequences of pregnancy, or complications arising from childbirth. ${ }^{1}$ And, so as a community, it is natural that significant research efforts have been targeted upon these particular health concerns. When I began working in this growing area of "women's health," it was within this domain-initially through a workshop at CHI 2013 on "Motherhood and HCI" [17]. At the time, I was reading Sara Ruddick's work on maternal thinking [80], and reflecting how we design such that we can care with and through technologies. As some kind of response to this, and with a team of others, I designed, developed, and deployed FeedFinder-a mobile application to support public breastfeeding $[14,86]$. A series of interactions that embody a promise to allow breastfeeding people and others to care for one another by providing practical, location-based resources may create a feeling in which public breastfeeding (in an otherwise unwelcoming context) becomes a possibility. At the time that we made FeedFinder, I was really thinking that it would be relatively "easy" to make a mobile application that could support women in breastfeeding in public. It was not really until afterwards, as I reflected on the design and its subsequent deployment, that I realised the political consequences of the design work, and that its consequences spanned the personal (e.g., do we think that the best infant feeding option is breastfeeding?), legal (e.g., are we suggesting that women should only breastfeed in certain locations?), and practical (e.g., do we interfere with the mother-infant bond by designing for the mobile?) aspects. The social, cultural, and political entanglements within women's health are nicely captured by Kumar et al.'s reflection over 13 studies in the Global South [60, this issue]. Here, the authors reject the categorisation of "health" and instead prefer to consider their work under the umbrella of "women's wellbeing." Health epitomises a way of thinking about the body, which is overtly medical-something to be fixed when broken, or something that needs to be managed and maintained; else, it might misbehave. This categorisation of "health" does not fully capture the social and cultural elements of women's lives and experiences, which reduce their capabilities. It does not capture the patriarchal societal and organisational structures, which influence how the body is experienced and cared for, and therefore it does not bring these structures into an analytical framework, which can be questioned, critiqued, and worked upon. Kumar et al.'s contribution to this Special Issue is to highlight why so much of the work that classifies as, or could be classified as, "women's health" can often be viewed as also having an activist or political agenda. There is recognition that what needs to change is not just the tools and technologies available for supporting women's health, but also the whole social and cultural system within which these bodies are categorised, performed, and enabled.

$\overline{{ }^{1} \text { https://www.who.int/gho/women_and_health/en/. }}$ 
Across this Special Issue, we see authors using multiple forms and styles of research to give voice to experiences that have been marginalised-from historical analysis to critical genealogy through to design memoirs. And, perhaps, it is not surprising that so many of these papers are developed from an activist perspective, whether it be self-identification as an activist-scholar [43, this issue] or unpacking how entrepreneurial activism can lead to social and political change [72, this issue]. And, of course, for many of us, the personal is political (small p and big P), and the political is deeply personal. We see this directly in action in Devendorf et al.'s [34, this issue] contribution to this issue, where the authors share extremely personal experiences and feelings, laying themselves bare to their personal experiences of motherhood, to claim this as a valid space for design research, to wager that their experiences matter too. But they also discuss how they put themselves at risk too by publishing this article-in a career so bound up in professional identity, how will such an admission affect their identities, their standing in the field, their tenure track cases? To me their stories and the objects they create are beautiful, emotionally wrenching and authentic, and speak to a desperate need to find new ways to have compassion within our design processes.

This idea that they risk themselves by doing research in this way resonates with my own experiences too. In the recent Special Interest Group on Human Computer Interaction and Health Activism [96], we discussed how certain topics of research and certain approaches to research were "risky" from an ethical perspective, a personal perspective, and an institutional perspective. We also discussed how those risks could potentially be carried by more senior members of the community in ways that would be impossible for junior members. That is, to "get into trouble" is a privilege in and of itself. And, I am troubled by this. What does it mean about our community, our jobs, and the institutions that we serve and represent if we are unable to do the research that we feel compelled to do because we are fearful about the consequences? As I think about this, and write about this, I feel that we could collectively take courage from Lorde's [64] writing on silence, language, and action. That to remain silent does not protect us from our fears, but instead forces us to become the face of the very thing we have been fearing.

I was recently called brave by a senior colleague for having undertaken research on intimate topics that relate to tabooed body spaces. I was told, and found myself a little shocked to hear, that I had put my career at risk by deciding to do research, and publish on bodily areas and functions like the vagina or menstruation. I have also heard that some considered our use of the word vagina in the title of a $\mathrm{CHI}$ paper on Labella [10] as a shock tactic, undignified, even though the title succinctly described the focus of the paper and technology. I find the ripples and stir caused by working with the body, its process, and materials strange. But, I recognise the laughter that Devendorf et al. [34, this issue] describe as a response to "the Nipple Poncho" when shown-this too has happened so much with reference to our design work. This laughter is important to talk about because this laughter is not neutral. We have used humour as a way of talking about, or making it possible to engage with sensitive or taboo issues $[7,103]$-and I would say it has been a common theme and approach to our design work in this area. So, by no means is laughter and humour a negative thing. Laughter can signify surprise, or relieve discomfort. But it can also be used as a way to belittle another person, or their work. It depends on who is doing the laughter and how it is done, but it can certainly be a communicative act that says something about what research can be about, and how it can be undertaken.

Shaowen. I appreciate Madeline's notes on the politics of researching women's health in HCI: from the need to support pluralistic agenda/visions of women's health research in our field to the pragmatics of doing women's health activism. And, I would like to respond to them in turn.

First, I would like to explore diverse relationships between women's health research in $\mathrm{HCI}$ and medicine as they inevitably become entangled with mainstream public discourse on women's health, and narratives and discourses of the topic have material consequences of what we do and 
how we do women's health research in the field. HCI, design, and health informatics research have sought to leverage new computational possibilities to contribute to individuals' ability to manage their health. From monitoring symptoms through tracking to visualising health-related activity to improved portals to interact with clinicians, HCI researchers are innovating on the capability of a diverse array of sociotechnical systems to improve people's access to health information and to understand and care for their own bodies.

In spite of a growing trend in HCI toward experience and embodied interactions, some topics related to the body are still viewed as marginal, especially in areas such as women's health and human sexuality. Women's health has an uneasy history with medicine [78, 79]. There has been a veil of secrecy around women's health for a long time. It really is not very many generations ago that women did not talk about any female health issue because it "was not proper." The fact that Teresa and Madeline's use of "vagina" in their paper received criticism is a case (among many others) in point. Healthcare providers have long dismissed or downplayed women's reproductivehealth and sexual-health concerns, a phenomenon known as "medical gaslighting" [39], which manifests in different aspects of women's health, including cardiac arrest resuscitation (Edmonds cited in [29]), pain (under)treatment (ibid), drug effects (research has shown that women have a 1.5-1.7 times higher risk of adverse drug reactions than men do), problems around contraception (such as Essure, which resulted in at least 15 women's death by the end of 2018), and dementia (women outnumber men two to one with Alzheimer's disease in the United States). Research has shown that not only do men and women communicate differently to healthcare providers about their pain, healthcare providers may also respond differently to them. As Hoffmann and Tarzian describe, "Women get prescribed less pain medication than men after identical procedures..., are less likely to be admitted to hospitals and receive stress tests when they complain of chest pain, and are significantly more likely than men to be 'under-treated' for pain by doctors" [49]. It is clear that general societal sexism is one of the key factors that contribute to the problems around women's sexual and reproductive healthcare.

The dismissal of legitimate concerns and symptoms and the lack of medical intervention for pain management and cardiovascular care are even more severe among women of colour. For example, African American women are three to four times more likely to die from childbirth than non-Hispanic white women, and socioeconomic status, education, and other factors do not protect against this disparity. Instead, sexism and racism are the primary drivers $[55,73,85]$. In the area of health research, especially women's health, we also need to acknowledge that our experiences of the body's materiality, affects, and sensations are always mediated and shaped by the broader sociocultural, political, and historical contexts. Such an acknowledgment necessitates our attention to characteristics such as, "race or ethnicity, religion, SES [socioeconomic status], gender, age, mental health, disability, sexual orientation or gender identity, geographic location, or other characteristics historically linked to exclusion or discrimination are known to influence health status" (US Department of Health and Human Services, 2011, cited in [25]).

Acknowledging the existence of multiple intersecting identities is a critical step in understanding the complexities of health disparities for multiple historically marginalised populations. This also means the need to recognise how social structures perpetuate social inequalities that contribute to health disparities. The recent attention in HCI to the topic of intersectionality $[42,82]$ illustrates the field's interest in this area; however, there is much work to be done to operationalise the theory for health research in HCI.

As editors of the Special Issue, we take an emancipatory and inclusive perspective and attempt to sketch what might a new feminist health politics look like. As Jeffrey Bardzell and I have argued [23], HCI and interaction design are increasingly engaging in issues related to social change, and in so doing, mixing both scientific and moral/political objectives, implying a potential con- 
flict between the goals of knowing truth versus doing good. To me, our personal/social perspectives and intellectual/scientific practices are inseparable, and they constantly trouble and reconcile the porosity of these two borders. While there has been a multifaceted research agenda focusing specifically on women's health in HCI, addressing topics such as menstruation and childbirth as a way to address historic disparities in terms of women's health, much of the HCI-relevant research on women's health has focused on younger women, specifically on menstruation, fertility, and pregnancy. Health issues of concern for aging women, such as an increased risk for osteoporosis [97] and menopause [21, 62], continue to be underrepresented in HCI research, which will be increasingly necessary as the population ages in the United States ${ }^{2}$ and worldwide. ${ }^{3}$ Research in $\mathrm{HCI}$ around nonbinary gender health [57, this issue] as well as reproductive justice for women of colour [60, 72, this issue] takes on more urgency than ever. These papers in the Special Issue give us a glimpse of the activist potential of health advocacy and an intersectional approach to health inequalities.

Pragmatically, this means that HCI will need to fundamentally rethink approaches that concern women's health and technology, and in one of our conversations, Lone suggested this could be a vehicle to rethink the relation between health and the body as such. This includes but is not limited to the following: resisting medical ideology that assumes a patriarchal assumption about women's bodies; challenging the medical objectification of the body (i.e., the reduction of the bodily experiences to a set of symptoms); prioritizing women's voices and experiences as the starting point for intervention $[8,34,59,72$, this issue]; pursuing collaborative and systemic action to promote health equity [43, 91, this issue]; overcoming disparities in healthcare quality and outcomes for gender (including people who are transgender) and race [57, this issue]; supporting new understandings of what does/should count as "medically significant"; addressing theoretical and methodological challenges; and taking advantage of emerging technologies to engage and even transforming the social dimensions of women's health, among others. Such steps will position HCI research towards contributing to solutions, rather than the problem.

Lone. I completely agree with Shaowen in that there are many implicit agendas at play in approaches that concern women's health, bodies, and technology. When we talk about aiming to "fundamentally rethink existing approaches," we are making a feminist response to the research agenda. We are speculating how we might rethink the relation between health and body as such, and in more general terms, this is a way of trying to see the world differently from if we look at it from the unmarked position of the middle-class cis-gender male. In this way, as Madeline discussed, doing research within the women's health domain is difficult to do without also being an activist (or without bringing an activist stance into research). Feminist scholar Sarah Ahmed reminds us throughout her writing (talks, blog, books) that combining activism and research is not a bad thing, though, but I think we all find it important to recognise our nonneutral stance. This is critical women's health in HCI, and the prefix "critical" matters to us as well as to the papers in this Special Issue. As a collection, they highlight the many areas where work still needs to happen for HCI to become truly diverse, particularly in some of the more complicated areas to undertake research. It also reveals that one important aspect of this is to create a supportive community of researchers invested in understanding how we might resist the idea that there is a "neutral stance" in research in the first place. In this sense, as a feminist response to women's health in HCI, this collection of papers is a call to continue moving from women's health as primarily a medicalised problem-solving discourse to a critical engagement with the way that women's bodies are conceptualised in and through technology. What we are also witnessing in this issue is that activism

\footnotetext{
${ }^{2}$ https://www.census.gov/newsroom/press-releases/2018/cb18-41-population-projections.html.

${ }^{3}$ https://www.un.org/en/development/desa/population/publications/pdf/ageing/WPA2017_Highlights.pdf.
} 
can be done in many ways, and that there is no firm agreement on what (critical) women's health research is even if there is agreement that it is important.

If we look at the papers in this Special Issue, several of them reminded me that a feminist way of responding is also to figure out ways of living with uncertainty. For instance, Devendorf and her collaborators [34, this issue] argue that in the case of design and HCI, we can also let uncertainty drive a response, and in some cases, this response will also be a matter of figuring out ways of coping. Their work has prompted them to think about "how to design with and for the unforeseen [...] and to resist our desire to quantify the unforeseen" (p. 22) because they saw a need for dealing with uncertainty in a different mode. This resonates with Søndergaard's contribution [91, this issue], in which she argues that shifting the framework from "problem solving" to "troubling" opens up other ways of configuring the connections between humans and computers.

Furthermore, I find that the discussions in Devendorf et al.'s paper [34, this issue] on how the often-used "wicked problem" framing was not useful to them are a lovely take on how theoretical framings matter to what we as researchers see, and it is in line with several of the other papers in this Special Issue even if they approach it differently. So when Devendorf et al. state that "perhaps framing women's experiences as the inspiration for 'problems' has served design regimes that implicitly found only certain kinds of situations worthy of masculine/hegemonic interest," the authors highlight an important aspect of us making this Special Issue in the first place: We firmly believe that it is important to insist on the need for a new feminist health politics in general, and in $\mathrm{HCI}$ in particular. And this has to do with what is "worth" researching, both in sociocultural terms and in monetary terms: where lies the prestige and where lies the funding. More importantly, however, we need to bring a feminist response into this area of HCI (too) because to a research field it matters that many types of voices and perspectives are heard, not simply as a democratic principle that seeks to give space to all kinds of researchers and people, but in a more fundamental manner: More situations will have to be found worthy of interest. This issue is one step further in that direction, and several of the papers argue (implicitly or explicitly) that there is a huge opportunity for HCI to explore not just new areas of interest but also new ways of dealing with the world and other ways of addressing the complexity in it. This needs to happen with care and compassion, be it towards gender inclusivity, be it embodied ways of bringing digital technology into people's messy everyday lives, or be it through leveraging the power of speculative design to imagine new sociotechnical structures. To me, this is a callback to Shaowen's work on "Feminist HCI" [22], in which she writes that "[...] using software constitutes users as subjects; that is, it makes us become the kind of user the software is for, bracketing aside the rest of ourselves that is not relevant to the software. The software gives us an identity that we are pressured into accepting."

Arguing for a new feminist health politics starts here, I think: Software and digital technology frames and is framed by the people and communities with which it interlaces. This means that it is important to recognise how research into design and HCI is actively co-creating many kinds of identities; particular kinds of being in the world with/through the software, services, and devices are made harder or easier. As Madeline said in the beginning of this conversation, her work basically began by asking "how we design such that we can care with and through technologies," and to me this is key: How does technology care, to whom does it care, when does it care, and how do we work with the design of technologies in a careful way, in ways full of care? To me, this is part of what a new feminist health politics must work from. So in some ways, moving towards a new feminist health politics is to continuously recognise that in the matter of $\mathrm{HCI}$ and health/body, we have an obligation as researchers to stop implicitly assuming that in design of technology there is such a thing as a neutral user-because when researchers do this, the assumed users often hold the unmarked position of an able-bodied cis-male from the middle class in the Western parts of the Global North. 
Teresa. There are so many relevant observations from all of you, Madeline, Shaowen, and Lone. I would like to look more closely at some of them. One is that of what is "worth" researching, as you say Lone, and how that is perhaps entwined with funding opportunities and overall prestige (therefore the danger of laughter?, as Madeline has commented on earlier). A few years ago, when Madeline and I started our design work and research on pelvic fitness, first through a very crafty toolkit [9] and then with Labella [10], we did not know that we were entering such muddy waters. Or at least, I did not. I do see it now, but has only been through commentary such as that you mentioned Madeline, at least that you are "brave." In my case, I have heard from senior colleagues who have said the work is "stupid" or have called me "disgusting" for even saying vagina, or from demoing Labella in tech conferences [11] and having women colleagues quickly withdrawing from my demo space the moment they see something like a piece of underwear or any mentioning of pelvic exercises (too sexual to handle?), or the nervous laughter, which I now recognise as mostly discomfort, even if dismissive. Back to prestige and funding, and we can see where this is all going. I, however, remember one article from Virginia Braun that at the time helped me in putting it all into perspective, "Breaking a Taboo? Talking (and Laughing) about the Vagina" [26]. Perhaps better known within HCI for "thematic analysis," Braun wrote her PhD thesis in 2000, and in the field of social sciences, titled "The Vagina: An Analysis." "Talking (and Laughing)," a short article written while a PhD student had it all, from the difficulty of researching troublesome topics to being stigmatised by colleagues, or the embarrassment of speaking about our own research. How I too omitted and lied when sharing the work with different networks of people! Besides, there seemed to be little to no work exploring any of these topics in early 2013 when we started, or real funding opportunities for when we finished/were looking to expand in 2017 (even the "wild card" category was far-fetched). Either way, two decades later and Braun continues to pursue a career around these topics, so there is that. And in HCI, there are more researchers seemingly and actively interested in talking about such (still?) "troublesome" topics.

Still, and similarly to Braun's own practice in and experiences of sharing her research, it has been all these responses, which "have ranged from fascination and interest to horror and complete disbelief" that is the foundation for much of the work we have done together. The designerly work shared in workshops and a realization of how "we do not even know that we do not know" [100], in tandem with a lack of access to resources or the taboo associated with touching the body, showed us how these are some of the many constraints to embodying knowledge in intimate care. So, how could we in our research field care for and with what was also contested, complex, or disputed in other fields too? The research did focus on the anatomy, but in wanting to challenge notions of anatomy that are derived from medical knowledge and that focus so much on reproductive systems. So much so that any other "part" is relegated to a second plane. This again, and as already mentioned by Shaowen, falls in line with the historical politics of reproduction, one in which knowledge is produced based on who is engaging in the research and who decides what needs to be known and should be funded. A few years ago, feminist philosopher Nancy Tuana argued for this knowledge-ignorance nexus [100], and her epistemology of ignorance within women's health (the case she discusses is orientated and based on the women's movement) continues to resonate with everything we talk about to this day. To give an example, the ignorance produced by conceptualising genitalia via reproductive function is striking, in particular that such knowledge (or lack thereof) continues to be delivered in such a manner for the most part of sex education programmes across countries, or that "parts" such as the clitoris have just very recently been understood or studied in more detail.

In the medical realm, discussions and devices that involve, e.g., pleasure, also appear to be quite marginal. In 2019, I attended the first world congress on Women's Health Innovations and 
Inventions, ${ }^{4}$ and while impressed with the range of topics covered, I was also disappointed by the seemingly medicalised approaches to the treatment of, e.g., menopause, or the "FemTech" technologies on show, all exploring overarching topics in HCI research, e.g., fertility tracking. However, discussions and devices that involve, e.g., sexual pleasure were quite marginal in this well-attended conference. Women's health and pleasure was packed in one session only, and a session that took place in one of the smaller rooms available. Nonetheless, it was crowded-with mostly women attendees, in an event that was visibly and more prominently attended by men. All in all, no wonder the view is so instrumental, even I left after a few days thinking if hormone replacement therapy could be the one way to care for my aging body, and that eventually there should be little to no fun or joy if surrendering to it.

I will revisit Tuana's taxonomy [100] to reflect on how institutional structures hold the power to render individuals, or groups of people, "ignorant." This can be seen when woman-centred technologies are "pushed" for the purpose of profit, e.g., oral contraceptives, through the dangers associated with technology-enabled artefacts that sit within the body, e.g., heart valves designed for the one-size-fits-all anatomy. As the three of you have questioned before, how can we design technologies with and for care, and who cares? As mentioned by Shaowen, this implies mixing the scientific and the moral/political, and for many of us, the personal is political, and the political is deeply personal as per Madeline's comment. In wanting to advance a new feminist health politics, I hold on to Lone's final remarks too, that in designing technologies there is no such thing as a neutral user-for all the reasons already introduced in this section, but also as a way to embrace and develop women's health in HCI from what it was before to what it will become next.

\section{WHAT MIGHT “WOMEN'S HEALTH” ENCOMPASS IN HCI, WHAT GETS CAPTURED, AND WHAT GETS LEFT BEHIND}

Shaowen. As we speak about the politics of feminist health research, we also need to grapple with the question of what it means to do women's health research as "women" in the postfeminist era. Even as we and others position "women's health" as an emancipatory research agenda that seeks to improve health and wellbeing in part by recognising how health is implicated in histories of oppression and injustice, women's health is also being criticised for reifying a binary conception of gender and thus contributing to histories of oppression and injustice. The argument is that as a formulation, "women's health," which commonly focuses on issues including pregnancy, menstruation, menopause, breast cancer, and so on, seemingly excludes nonbinary and transgender identities and in so doing further marginalises them. While I agree with this critique, and I accept that gender is nonbinary and acknowledge that health services for individuals who identify as gender queer are in even worse shape than those for women, I have had a harder time finding an appropriate research language to reflect these beliefs. I am reminded of several conversations I had with you three, Lone, Teresa, and Madeline, about many practical difficulties during the reviewing and revision process of several articles in this Special Issue.

For example, I was faced with practical questions, such as the following: Is it acceptable to refer to menstruation as a "women's health" issue when we know that not every woman menstruates and not all who menstruate are women? What happens when reporting empirical data where the subjects themselves speak of menstruation or pregnancy as "women's issues" in a way that implies a binary conception of gender? How can we acknowledge the emancipatory achievements of feminism in general and feminist approaches to "women's health" in the past, while still remaining critical about their tacit perpetuation of gender binarism? Should research on pregnancy, menstruation, and so on avoid the word "woman" in favour of phrases such as "pregnant

$\overline{{ }^{4} \text { https://whii2019.comtecmed.com/. }}$ 
individuals" or "people who menstruate"? Consider the phrase "a woman's right to choose" a phrase whose political efficacy has served as a rallying point for millions over decades, crystallising and motivating support for rights, including birth control and abortion. If the term "woman" becomes a suspect, so does that phrase and all it has come to mean. But if we strike that phrase from our vocabulary, we also seem to discard its political efficacy.

"Women's health" faces a similar dilemma. As the formulation is critiqued for its apparent exclusion of nonbinary gender, and replaced with a language that reflects intersectionality and queer theory, does that move obfuscate the emancipatory achievements of the researchers whose work called attention to and intervened against misogyny in health research, including in HCI? Many feminists hold the position that feminism can and should be used to advocate for other marginalised individuals, and that feminists' constructions of "woman" often can mutatis mutandi be adapted to advocate for trans, subaltern, Black, indigenous, and other positions subjected to hegemony. That is, the construct "woman" is not understood as bearing essentialist commitments, but rather relational ones. In other words, instead of proposing an essential transcendent difference between men and women, the construct instead highlights the asymmetry with which those concepts are relationally deployed in discourse and practice. Such asymmetric relations include normal:other, centre:periphery, and natural:deviant.

For all of these reasons, I believe that treating "women's health" as if it were hegemonic in the same way that traditional health has been is, in my view, a false equivalence and a denial ofwomen's health activists' labour and impacts. Even so, I remain troubled by the potential of "women's health" to reify gender binarism and to marginalise people. In such a spirit, I welcome a robust and thoughtful debate about nonbinary gender and ways to improve research language to meet our values of diversity and inclusion, but I hope the community does so without turning our backs on those "predominantly women (sic)" whose labour helped to establish and legitimise the very emancipatory frameworks that are now being used to critique them in turn.

Lone. To say "I research women's health in $\mathrm{HCI}$ ” without also being (understood as) political is surprisingly difficult. It quickly becomes activist research both because it often/always touches on topics that are overlooked, tabooed, or marginalised and because this research also has a feminist agenda: It seeks to intervene into a research field that has basically been blind to its own gendering. And as Shaowen says, during the editing of this Special Issue, we have had long discussions about how to talk about "women's health in HCI," be it as a topic, or as a word, or as a research practice. What worlds are made visible and possible through the research presented in this Special Issue and in the research leading up to it, we editors have asked ourselves several times. This topic brings many dilemmas to the surface.

In STS scholar María Puig de la Bellacasa's book "Matters of Care" [77], we are reminded that "ways of studying and representing things have world-making effects" (p. 30), a central aspect in our reflections on what "women's health in $\mathrm{HCI}$ " captures and what it leaves behind. Echoing Haraway's already immortal words about mattering [46], and drawing on Mol's notion of specificity in care practices [68], Puig de la Bellacasa extends Latour's "matters of concern" [61] into considering "matters of care": "fostering also more awareness about what we care for and about how this contributes to mattering the world" (p. 41). In a way, Puig de la Bellacasa [77] calls for ethically and politically charged practices, and while I applaud this, as I think we all three do, I guess that this charging will always be a work in progress. To me, Puig de la Bellacasa's thoughts about matters of care are interesting when pondering the meaning of women's health in HCI. It has to do with what we care for but also what we think needs to be taken care of. Specifically, I think that two contexts are important to consider with respect to what women's health research cares about. Or perhaps rather, to give this an active form, what women's health research in HCI "activates" and intervenes into: the larger societal context (how women's health is positioned) and 
the HCI research context (what we might call marked and unmarked voices and interest areas). Both are highly politically charged.

In this Special Issue, we see how influential the 2016 work by Teresa and Madeline has been in prepping the ground for thinking about women's health in HCI, work that builds on Shaowen's work on Feminist HCI in 2010 [22]. Keyes et al. [57, this issue] refers to Teresa and Madeline as the first researchers in HCI to use the term "women's health" to express design and HCI research that seeks to use digital technology and design to address problems that lie within the already existing medicalised field of "women's health." And while Keyes et al. points at potential blind spots in the research since 2016, it also recognises the work's significant impact [57, this issue]. Also in this special issue, Almeida et al. [8] looks back at their previous work in order to move forward, and your focus on how design research should seek to induce change, which resonated with me in several ways. Both of these papers address how design practice also makes manifest particular understandings of gender, societal value(s), and research community preferences, all of which always also condition what counts as "proper" or "marginal" research in HCI.

When planning the Hacking Women's Health workshop at CHI17 [16], we struggled with marginalisations in several ways, for instance, in that we faced a few discussions with nonparticipants concerned with if the workshop was too political for CHI [15]. It still puzzles me that some seem to think that $\mathrm{CHI}$ should strive to be politically neutral, as if design of technology is not already always political, but let us return to our specific concerns. To me, this concern is connected to how research in women's health in HCI implicitly highlights societal differences with respect to, for instance, how access to healthcare works, what counts as healthcare, and how we even think of healthcare, of gender, of bodies, of class, and of "healthy bodies." Societal structures are very visible in this type of research, and it also very quickly concerns women's rights, which catapults us directly into a highly politicised territory. Not all countries operate like the United States (luckily, I would add), but like all research in HCI, women's health research is also marked by a Western (especially American) understanding of society. And even if many of the papers in this Special Issue specifically address other cultural contexts (Taiwan, the United Kingdom, Europe, India), the health politics of the United States is difficult to ignore.

We all have had comments on the political agenda of our research, including being asked if it is politics or "real research." This connects to the broader issue of gendering in/of research: what is being studied, who studies it, and how do other researchers respond. Again, I will turn to discussions within STS, where Stengers and Despret unfold in [89] how gender and science discursively interweave. In a long and interesting conversation, they discussed how, on one hand, science is never coming from a neutral place, whilst, on the other hand, the very act of pointing out that knowledge is never neutral results in one's own research being marked as a particular-which to female researchers often means "clearly" feminist, biased, and thus not "true science." It is frustrating to have the relevance of the research questioned simply because it is explicitly interested in a "marked perspective": voices and people who are marked as "different" from the norm (i.e., the white middle-class cis-male researcher from a well-funded university in the West). This is an impossible dilemma, as Stengers and Despret show, and it is fascinating and heartbreaking at the same time. We see this in HCI too, even if it has improved greatly over the last years, in no little part because of the research activism that many from our research community have taken on.

Because of this blindness in HCI, marginalised voices have had a hard time. In a way, by foregrounding women's health in HCI, with this issue we also seek to show how HCI as a field has dealt with genders, bodies, and health for a long time already, although the centring of the unmarked position needs to change; all papers in this Special Issue reflect on their own positionality, and all papers are in some ways part of an activist agenda in changing how we think of HCI as a field, also by demanding that it is important to centre what is often considered the margins, thus also 
echoing Shaowen's Feminist HCI paper from 2010 [22]. This does not mean that all researchers have to be activists, but it does mean that when more HCI researchers understand and declare their positionality, it (perhaps, or hopefully) becomes easier to see what is and is not studied, and how conditions for doing research have an effect on what we as researchers can do.

Returning to the question of what to call this, we face a dilemma of a different sort from what Stengers and Despret describe [89], but I find it equally dilemmatic. If we replace the word "woman" for something else, we would get rid of the problematic gender binary. However, we would risk making invisible some of the inequalities that affect a large number of people. For instance, in Denmark where I live, the word for "domestic abuse" is literally "wife abuse," and there is some discussion about changing it to "partner abuse" because it would verbalise that not only women are abused by their partner. However, since women are disproportionately affected by this, it would make the statistics discursively invisible. Sometimes words, as well as research practices, reinforce the very structures that it was hoping to dismantle; and because language makes things visible, picking the least violent language is not always easy.

Teresa. As just mentioned by Lone, it is true that language matters and makes things visible. That there might be failure in language, yet a language but one that it is constantly evolving. It is crucial to attend to such developments as we move forward together. And, importantly, to acknowledge that what we may find written under the banner of HCI these past few years, and specifically in those that deploy with "women" as a main group of study, were a product of what was available at the said time. Including that "women's health" was absent from HCI until recently, which not only suggests catching up with an entire field within health research (which HCI is so active on, though apparently biased) but also to critically engage with and address the conceptual limitations of women's health or evolutionary approaches to health more generally. Because actions also matter, taking action is needed, and we learn from doing even if along the way we fall short of delivering are misunderstood or misrepresented. It is uncharted territory and as such the important thing is-it has been-that we try. To borrow from a famous quote of Samuel Beckett, we can only try again, fail again, but fail better.

As pointed out by Shaowen, I too see the lack of symmetry as critical to the "women's health" paradigm. For example, in our paper [8, this issue], we are taking a human-centred and perhaps a more-than-human approach to design, and one that certainly aims at accounting for all humans. The focus on "woman," just as in much of our previous research, has been essential to highlight existing disparities and perpetual inequality-for the most part, disparities and inequalities that are very relatable to some of us. This is not to emphasise the differences between men and women as a way to move forward, but instead to show how certain areas in the research continue to be given less attention or are wrongly deemed of interest to the few. In other words, such research is not relevant enough (!). This, too, perpetuates violence, stigma, and harms a great number of people. That is to say, such a category of people as "women" keeps being overlooked, as much as any others that do not fit with the status quo. If nothing more, and whether praised or contested, the work that we have been doing seems to have given an opportunity for these different groups, including women and nonbinary, to become more prominent, while bringing to the fore a wide range of systematic issues that similarly had not been considered before and that yet again resonate differently with different subgroups. Also, it has contributed to extend the conversation on tabooed topics of, e.g., sex and sexuality, which some ACM publications understand as more troubling than others. To give an example, I will use the case with the issue of XRDS: Crossroads, The ACM Magazine for Students in which Ahmed and I worked together as guest editors [1]. Shortly after the issue was out in print, we published a short piece at CHI 2018 alt.chi on the event, one that included reaching an agreement with the salaried editorial team based in the main headquarters who, among others, were keen to remove the actual "experience" of "bodywork" from any of the content and, 
e.g., we/authors were asked to make all references to sex "as clinical as possible" [3]. I mention this not only because it resonates in content with our overall topic but, in particular, to reflect on the politics of publishing in the venues we sought to publish in. Generally, less-than-transparent policies suggest that "what gets captured" might depend deeply on, e.g., editors, reviewers, implicit biases, or timing, and "what gets left behind" is all that does not look "safe" to the status quo. I would say that Women's Health in HCI has been within that spectrum, one of rigid understandings of what is acceptable in research and that which is constrained by the "objectivity" of clinical language (scientific? Our work has in fact been commented on as "not being scientific enough") and "neutrality": How can we as critical health researchers be neutral about our subject (the body)? Or better, why should we? I think it is only when addressing these questions that we can then work around the asymmetry in all its dimensions, both in theory and practice.

Madeline. Teresa, Lone, and Shaowen, you have very eloquently argued as to how the words we use matter, and the actions we take make things visible. There has been substantial work undertaken to find a place for research of this kind, and that work has happened within institutions and cultures, which have impacted on the words we have used, and the actions we have been allowed to take. My heart sings to read Lone's interpretation of "Labella" as being "prepping the ground" for more research and design in this area, and at the same time, my heart has felt so low to read alternative perspectives of the impact of this research, and the violence that it has inflicted on others. So, I want to speak a little to this, and to one way that I have found it possible to keep constructively moving forward these last few months.

As Almeida et al. introduce [8, this issue], it is still the case that inequalities that exist at every intersection-racial, class, disability-disproportionally affect those who biologically, socially, or culturally align with the term "woman." So, as both Lone and Shaowen indicate, it is difficult to stop speaking the word "woman," or to stop thinking along the category of "woman" when aligning oneself with "woman" results in so much harm and inequality. The ways in which words lead to inequalities associated with "woman" are made plain in a number of the submissions to this Special Issue. For example, Ng et al.'s exploration of the political and social work undertaken by the entrepreneurs and feminist activists who launched the Formoonsa Cup in Taiwan [72, this issue]. In this text, the authors describe how warnings were published on tampon packets up until 2009 to warn unmarried wearers of the consequences of using such a product during menstruation. While these warnings no longer persist, they continue as social and cultural knowledge, influencing how the Taiwanese population thinks about the value and expectations of the unmarried woman. In terms of the area "women's health," it should be clear that the way things are labelled, described, designed, and made impacts on who is included, who can participate, and how a research area/specialisation might be perceived. And as Keyes et al. remark, it is our responsibility as researchers working in this area to be conscious and careful not only in terms of how we are framing our work in this space, but also being explicit about who a particular framing is leaving out [57, this issue]. Design research around women's health and bodies has been so generative exactly because when we attend to the body, seriously, to its materials and experiences, we can design in ways that lead to fundamentally new interactions and opportunities. But we must also be able to articulate where we have not done our research. That is not to say that those bodies and experiences are not valid and important, but that it needs further work.

And so, as we-even if there is a "we"-move forward, we should be cognisant and careful in how we act, what experiences we decide to explore in our research, as well as the words and language we use in how we recruit participants to our projects, in order to ensure we do not privilege only the voices and experiences in the (White, hetero- and cis-) mainstream. This is not about political correctness, or using politically correct language, but instead about respect-respecting people's 
rights to self-identify, and to self-emancipation, and respecting people's right to be and to feel included.

I am delighted that within this Special Issue we see examples of how research in this area can account for the voices and experiences of those at the margins. For example, I find hope in Fox et al.'s paper [43, this issue], which presents a series of in-depth explorations of people's experiences of menstruation and menstrual-tracking applications. Through their sensitive and divergent research methodology (which includes design workshops, and also posted design packets-allowing for private involvement in a research project, which might have otherwise been troubling and difficult), they are able to witness the experiences of a diverse group of individuals, and through drawing on these, they offer a different vision for menstrual technologies, which heighten menstrual sensemaking and offer multiple ways of knowing and interacting.

However, within Keyes et al.'s analysis [57, this issue], we begin to understand that drawing attention to certain kinds of problems, and certain kinds of bodies, what might be understood as "women's health" research in HCI has ignored and indeed further stigmatised other bodies who sit in the margins. Keyes et al. do some of the necessary work to draw attention to this blinkered view of the body, which we have perpetuated, and argue that rather than use the term "women" we should instead talk about "marginalised" health [57, this issue]. But-as Lone, Teresa, Shaowen, and I have discussed on multiple occasions while putting together this Special Issue-to describe the bodies and healthcare of those who are not White, able-bodied, cis-gendered, heterosexual as "marginalised" is in and of itself problematic. It led me to question why we should identify as marginalised, when we could identify as many other things, and where there could be so much power in identifying differently. Looking across the different accounts of gendered bodies, abled and disabled, wealthy and poor, Black, White, and Brown, there are multiple issues that are in desperate need of recognition and focus from design and technology. I find Haraway's notion of the many-headed cyborg almost reassuring. Perhaps there is no "us," and perhaps this is OK [47]. I myself do not want to be continually splitting and fragmenting away from researchers I admire and am inspired by instead of searching for some new essential unity with others. Instead, I think we need to look for a "conscious coalition" of researchers [81] based on some shared affinities, rather than a collective and unifying identity. There will be differences among us, among the bodies that we know, the experiences that we have, what we research and design for, and we will have at times contradictory standpoints. But, building on the work of many feminist thinkers [47, 64, 81], I do believe that we can choose to use these to our advantage to see things from many perspectives in order to reveal things about the world we live in, and design and technology's role in this world. In proposing this as a way forward, I also learn from Ahmed's writing on wilfulness [4] -that although we may not always agree, we need each other as a form of feminist support to help each other withstand the pressures that come with going against the flow.

\section{WORKING WITH THE MATERIALS OF THE BODY}

Lone. I like this term, "conscious coalition": We do not have to agree or seek common ground in order to work for the same thing. Perhaps we can also think of it in terms of the figure of "the multiple" from Mol's excellent book "The body multiple" [67]? The figure of multiple ontology describes parallel and interweaving worlds that sometimes overlap and at other times are incredibly far apart; they are the same and yet not the same at all. Sharing affinities-whilst being open to how contradictory standpoints are both frustrating and invigorating-works with this figure, I think. Furthermore, I think that understanding the value of dissensus is a feminist essential.

Another feminist essential is that emancipation is closely tied to knowledge and agency, also with respect to one's own body. The Danish version of Our Bodies Our Selves, "Kvinde kend din krop" (now in its fifth version since 1975), emphasises that "we need to demystify the female body, 
and to make our experiences matter" ([40], p. 8, my translation). And thus, the book has always been incredibly concrete in describing the look and feel of cervical mucus, vulvas, penises, breasts, menstruation, fertility tracking, sex, aging, and many otherwise tabooed topics; the logic is that it is through and from the body that people will learn to stand firm. In some ways, we find the legacy of this important book in Søndergaard's doctoral work, which I was fortunate to supervise; the core idea was to see how we might design with taboos of the body in order to investigate how digital technologies (and HCI+design practice) shape and frame actual and cultural bodies. In investigating how the body is (and can be) expressed in digital interfaces and services, the design projects and research papers that emerged from this project were concerned with at least two things: How to "trouble" through design practice (see also [91, this issue]), e.g., by confronting taboos, and how to use design explorations to discuss how the body, in particular the female body, comes to life in digital technologies and services.

That the body becomes the material in women's health research is clear, and it is equally clear that these bodies are messy-concretely, figuratively, as well as culturally. We see this expressed in various ways in this issue, for instance, in the Formoonsa Cup [72, this issue], the app critique [60, this issue], and Devendorf et al.'s [34, this issue] discussion of different kinds of messiness. Devendorf et al. present a careful critique of the discourse of "technology will help us be better parents" (my paraphrase). The three design interventions described in this article beautifully address how we might reconsider ways that people (mothers, potential parents, caregivers) are shaped through the technologies and the people they are surrounded by. The design interventions use technology in a broad sense, and this article gives a welcoming and sharp but also poetic and vulnerable perspective on how we need to be better at understanding the relations between a burdened body and the so-called helpful technologies.

The body is a cultural and political entity, and the premise of both the American and the Danish versions of Our Bodies, Our Selves was that through understanding the body better, women can be better equipped to participate in their cultural and political emancipation and empowerment. In connecting body awareness to questions of power, Btihaj Ajana uses the term "biopolitics" (how bodies are subject to governmentality) to analyse how the body is regulated through technology too, and how it is "made amenable to management" [6]. Following Ajana's lead, we see how everyday technologies are also governing and exercising power, which I think is an interesting backdrop to Devendorf et al. [34, this issue] and which Fox et al. [43, this issue] also get at when discussing cycle trackers. Some of those everyday technologies were part of my previous work with Søndergaard, because services, apps, and concepts also express a politics or understanding of the body as something to be managed and cultivated [92]. Most self-tracking technologies perform this type of work: pedometers (10,000 steps/day), sleep cycle apps, and so on are excellent examples, and while they are clearly helpful for the individual, they can also be read critically as instantiations of the productivity and optimisation paradigm. In this sense, bodily abilities and functions become a source for governance, a material that can be optimised and altered in order to serve a higher purpose. Sleep apps are particularly curious examples of how the body is materialised in design: Even in sleep there is no rest from being competitive. ${ }^{5}$ With respect to cycle trackers, Søndergaard and I had several discussions about how to compete in menstruation because it is obviously absurd even if it fits with the paradigm. However, if we think of cycle trackers as a fertility tool, self-governance is brought to the surface again and we see how also the otherwise invisible inside of an egg-producing body is visualised as a material with which babies might be built (if the body behaves as expected).

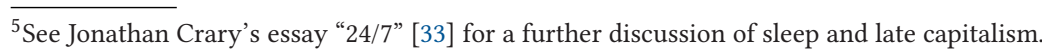


Teresa. That the female body has been a subject of taboo has limited the development of women's health and care in general. And the bodies through which we produce knowledge matter. Somewhat along the same lines as that you use to describe your work, Lone, I have elsewhere (but including in [8, this issue]) started looking at the materials that make the body as matter itself, accounting not only for the processes mostly through which our bodily functions are managed and controlled, but also in that "fluids with no potential" can contribute to change paradigms in women's health and health more broadly. Examples include bodily fluids, e.g., urine, that are implicated in the normal functioning of the body but also in its disruption, i.e., in/continence care; cervical mucus or saliva in the tracking of fertility-in ways that might differ from the "cycle trackers as a fertility tool" that you mention, Lone; or the vaginal microbiome and the design of technologies that use this existing fabric of the microbial body to maintain wellness. In working with the materiality of the body, here through making a meaning of its discharges, these technology-enabled innovations aim at providing for a more nuanced way of tracking bodily sex and subjective gender. Besides, I have long been interested in exploring notions of feminist biology and how biological knowledge can be a feminist ally, as discussed within feminist technoscience theory and practice [104]. Indeed, biological knowledge is political and biology is a material reality that nonetheless can be manipulated, e.g., by technology.

However, these technologies, as varied as hormonal contraception through to digital apps, fail to care for the interactions with the microbiological milieu, e.g., one that has the potential to produce, reproduce, or technically realign the body. Examples include fertility technology, which is already widely explored within HCI, and is directed mostly to women: We can see how for over a decade, digital technologies have been disrupting and transforming this industry, with a focus on family planning or making bodily information more accessible. This has an enormous potential market, as it extends through the lifecourse-from puberty to menopause. Nonetheless, and in parallel to the digital mobile apps we may study, these technologies (most of) involve a technical regime that produces a body via artificial hormones, one that transforms the boundaries of that body, e.g., the Pill, which suppresses menstruation only mimicking the period cycle. This can apply elsewhere, e.g., hormone replacement therapy for menopausal women, or masculinising hormones such as testosterone.

(Re)programming the body at the molecular level, e.g., by exercising, or through the microbiological milieu that accounts for the immune or nervous system, i.e, antidepressants, is one of a few ways that seem to have been available to take charge of or control our bodies, in whichever ways we may deem fit. Removed from a biomedical context and set in the everyday, exercise is said to, e.g., improve mood or boost energy, while low-intensity exercise is known to increase the body's insulin sensitivity too [98]. A myriad of tracking and digital technologies are readily available to support uptaking physical exercise anyway. More complex and underexplored then are the contexts in which and what interactions between the molecular systems of the body and, e.g., the Pill, can occur, and how those interactions can have an influence on mental health [88], or cause other adverse effects to a great number of women. We can see one such example by design in Søndergaard's work [91, this issue], in which a toilet-based voice assistant is designed to track hormonal levels and act as birth control-in this article, showing how pervasive these technologies might become in the future (or already are?) and to traverse areas of life that are the utmost intimate. But, I would say it is also opening up to the different possibilities to understanding the body, one that digital technology has embraced and reads (i.e., tracks) as code, as much more than an objective and coherent bio-artefact.

Culture, too, cultivates the different dimensions that materially compose the living body. In addition, we live in dynamic social environments and it is within these that "intraactions" matter, if borrowing Barad's concept of reciprocity between the biological and the social [18]. It is at the 
intersection of such notions of bodily materialism that I also see many possibilities for women's health research in HCI, in ways that attend to the "body" as part of a broader ecosystem and an ecosystem in itself, a body that is an indivisible part of lived experience and action. We certainly see that, e.g., in Devendorf at al.'s work [34, this issue], who rematerialize bodily data and offer it back to us in "a different way of telling," as one that "can be touched, felt, owned, given, shared and be spent time with" [34, this issue]; or in Søndergaard's accounts of living with electromagnetic hypersensitivity [91, 93, this issue], just to name a few.

Madeline. Teresa and Lone have both introduced and illustrated the varying ways in which technology reads and programmes the body, and the role of design in destabilising and questioning some of these dominant approaches. I want to add to this discussion a reflection on the Soma Design research programme that I currently participate in. The idea of the body as an indivisible part of lived experience and action is a key underpinning in the growing area of soma design $[53,90]$, alongside challenging the dualism between the mind (logical) and the body (messy and untrustworthy). In this sense, Soma Design could be categorised as a feminist project [53, 54].

I started to read and learn how to practice Soma Design in order to learn how to bring the body (or, more precisely the soma) into the design work I have been doing. In learning Soma Design, I have been training myself through slow, bodily activities, to attend to sensations within my own body, to be able to talk about these experiences with others, and to learn where we have common experiences and where our experiences differ, and then to move through a design process that privileges somatic experiences, which are pleasurable and interesting, and which accepts that all bodies are different, all somas are different, and that there can be no one universal approach to designing for these different somas, and different bodies. How we move, how we experience our bodies, and how we experience pain matter for the kinds of things that we chose to do, and ultimately the kind of life that we lead.

Elsewhere, Höök has written about how particular cultures prescribe certain things about the way that the gendered body should behave [54], for example, where I grew up, it was/is expected that women draw together their knees in public transport, so as not to take up space, so as not to touch, or be touched by others. According to somaesthetic theories, learning to hold my body in this way, to take up as little space as possible, to be polite, and to wait for others to go first, influences how I am perceived, how I think, how I experience the world, and, of course, how I am able to move. Taking the soma as the starting point for design allows us to explicitly acknowledge this within design. It is important, I think, to note, that Soma Design is not a neutral starting point, nor does it result in neutral designs. Techniques such as estrangement and defamiliarisation are common within Soma Design and are used to draw attention to the specific ways in which bodies behave and are supposed to behave. Soma Design can intervene in a way by designing interactions, experiences, and products that encourage and nurture new patterns of movements and experiences. In turn, this allows us to question how we have moved within the world, and through continued use and practice, this allow us to change how we are in the world, should we want to.

Bringing a Soma Design perspective to women's health has been fruitful. So many of the women's health experiences captured depict bodies and bodily experiences that are deeply entwined with uncertainty-a lack of knowledge or control over what is happening right now with the body, or the frustration that the body is doing what it is doing right now-a feeling of being let down by the body on a rather continual basis. What a Soma Design approach may give us instead is new ways of knowing about and experiencing the body, and from a generative perspective new ways of making ourselves feel comfortable at these thresholds [63]. Rather than seeking to change the body, to make it perfect, the emphasis can be placed on acknowledging and accepting the body as it is, and finding pleasure in the body that we have. 
The work undertaken within our research team in the last two years has sought to bring together Soma Design with women's health research. And, the integration of the two positions brings the work much closer to the materials of the body, to its substances and substrates, and to consider how we can bring ourselves closer to the bodies' materials in ways that do not prioritise quantification, but rather new ways of knowing through experience. For us, once again this means designing in relation to parts of the body that may be considered taboo, or off-limits, and at this point in time, this means menstrual blood and cervical mucus (e.g., [28]). In $\mathrm{Ng}$ et al.'s work [72, this issue], we are reminded that the materials of the body are not simply materials. These materials-what matters, what is noticed, what is designed for-are a sociocultural construct that is managed by individuals, communities, and governments, and each of these players influences how these materials are experienced and understood. For our research group, this has included the realisation that we cannot collect and undertake design experiments with our own menstrual blood or cervical fluids as part of our design research without access to a biomedical lab and approval from a national ethics board. This material, one that is produced by our own bodies, which we handle in different ways on a regular basis, is considered a biomedical hazard, which requires regulation and risk assessment as specialised equipment.

Shaowen. Madeline is right about starting with the body as the point of intervention for women's health research. At the same time, as both Lone and Teresa suggested, we also must confront taboos that limit talking about the body, in particular the female body. I believe that women's health must treat actual bodies and body dispositions as a focal point for research. I begin with an idea common in feminist thought, which is that our tendency to suppress or neglect the body in our thinking makes it easier to think and act in ways that harm people. The harm is right there in front of us, but we do not even see it. The feminist call for attending to bodies is not the same as HCI and design's calls to take embodiment more seriously, though that is important, too. Rather, it is a way of understanding sociotechnical infrastructures starting with the dispositions of human bodies within them, rather than such systems' technical features and capabilities. That is, it includes a focus on what our bodies are doing and not doing; the forms of physical suffering (pain, entrapment, boredom, diabetes) that sociotechnical systems contribute to; and the denials of pleasure (including breathing fresh air, self-expression, social interaction, experiencing sexual gratification, and purposeful action) likewise inscribed into them. In so doing, it also encourages us to notice the ways that future technologies will participate in social conflicts, e.g., by differentially positioning male, female, and trans, Black/White, old/young, citizen/immigrant, and poor/wealthy bodies.

One of the ongoing challenges in working on women's health in HCI is how best to frame the research. The act of framing does political work as it bounds the experience and conditions how research participants and ourselves approach the research.

The "framing" challenge manifests in different forms in our work to curate this Special Issue. For example, Keyes et al. (in this Special Issue) advocate the need to shift the framing of "women's health" to "health for marginalised bodies" [57, this issue]. Needless to say, I fully support the demand that all marginalised bodies should benefit robustly from health research and healthcare. Statistics about queer bodies are particularly disturbing, with unconscionably high rates of physical violence and suicide "outcomes for which all parts of society, including healthcare and health research in HCI and beyond" bear some responsibility. Whether doing so requires the research community to dismantle the framing of "women's health" is trickier, as explained earlier.

Regardless, there is strong consensus among the editors and contributors of this Special Issue that an important part of decentring the cis-male body as the "normal" is to insist that other bodies must not be marginalised, whether they are female, queer, disabled, sub-altern, poor, or Black. All these bodies are not only normal, but they also outnumber the stereotypical abled cis-male 
body. The practical question-and here is where the consensus begins to fragment-is how best to advocate for these diverse bodies, e.g., by strategically collapsing distinctions among them to create a supercategory ("marginalised bodies") or by maintaining distinctions among them.

Both positions have attractive and problematic aspects. The supercategory mounts a direct attack on the abled cis-male body as the default, leveraging the combined contributions of all the diverse bodies that constitute that supercategory. The main disadvantages are that "marginalized bodies" as a construct is like "woman of colour": It groups incredibly heterogeneous identities merely on the basis of what they are not (i.e., White men) (see [71]), and as noted earlier, it effaces the specific emancipatory histories and achievements of scholars working predominantly with one of those identities (e.g., feminist, queer theoretic, neo-Marxist, and postcolonial contributions become blended). Stated more strongly, the supercategory itself can become a form of domination: As Patricia Collins argues, "any matrix of domination can be seen as an historically specific organization of power in which social groups are embedded and which they aim to include" [48, p. 228].

Yet keeping the group identities separate, while avoiding some of these problems, brings risks of its own. One is the potential of working at cross-purposes, as in the case where "women's health" might seem to perpetuate a binary conception of gender, undercutting a foundational claim of queer theory and adversely affecting health for LGBTQ+ bodies. Another is that certain areas might become over- or under-represented based on academic trends, reviewer predispositions, and so forth. Finally, there is the risk that as individual agendas, all will be viewed by the broader community as niche topics, thereby failing to reach the critical mass needed to decentre the abled, CIS-male body in health research.

As a community, we can and will debate the merits of these different positions, but even as we do so we must make practical decisions now that take positions (whether we are ready to or not). For example, in $\mathrm{Ng}$ et al. [72, this issue], my coauthors and I present the case of a menstrual cup design project in Taiwan, called the Formoonsa Cup, whose product development led to the change in the legal status of menstrual cups while challenging traditional practices and ideologies of hymen maintenance as an expression of "pure" and morally upright womanhood. The practical challenge for us was to represent what happened in Taiwan-that is, the actual discourses and expressions of stakeholders, the language of relevant public policy and marketing documents, and so forth-where concepts of "hymen" and "woman" were somewhat dated from the perspective of contemporary feminist and queer thinking in the West.

For example, in Taiwan at the time this unfolded menstruation was seen unproblematically as a women's health issue (thereby marginalizing queer bodies), and the hymen was seen as a single piece of anatomy that can "break" when an object, such as a tampon or penis, enters the vaginal opening. This understanding of the hymen has been challenged by the Swedish Association for Sexuality Education, ${ }^{6}$ who has convincingly argued that the hymen as understood in the past does not exist, and that instead there is a vaginal corona, which is made up of thin, elastic folds of mucous membrane located just inside the entrance to the vagina. Reflecting the linguistic usages in our data, our article also used constructions such as women's health and hymen. Reviewers of this article argued that because our article has an emancipatory objective, we as authors should refer to the vaginal corona, rather than the hymen. Yet the term "vaginal corona" did not appear in our data at all (except near the very end of the data collection period, when feminists in Taiwan began to adopt the language of the vaginal corona as well). We thus faced a dilemma: We could either do violence to our data set, censoring and speaking over Taiwanese feminists, or we could

\footnotetext{
${ }^{6}$ The Swedish Association for Sexuality Education, RFSU, published an information booklet in 2009: https://www.rfsu.se/ om-rfsu/om-oss/in-english/national-work/sex-and-relations/the-vaginal-corona/.
} 
perpetuate a dated and historically misogynistic construction ("the hymen"). Either way, we would perpetuate a social injustice against women. Our practical solution to this problem was to directly explain the debate to our readers, to refer to the "vaginal corona" when we were speaking generally (i.e., not about our data set or the case study) and to refer to the "hymen" specifically when we were referring to our data set and case study. Positively, our solution achieves a higher level of precision, both when referring to body anatomy and in representing the case and our data. Negatively, the whole article might seem to criticise Taiwanese feminists-a position we do not endorse-and is arguably harder to read.

The upshot of all of this is to stress that research framings and vocabularies are in flux, and practicing as an emancipatory researcher is anything but straightforward. There are good faith reasons to disagree on the framings and our linguistic usages, and because the stakes are so high, these disagreements can become heavily charged. My recommendation is above all to recognise that there is no single correct answer and that emancipatory researchers, while pushing hard for what they believe in, also must be cautious not to undercut each other for failures to meet certain purity standards about which the community has no consensus.

\section{CHANGING BODIES}

Teresa. The stigma attached to the body is real, and "what is normal" or "is it natural" are certainly two of the few questions that, entangled in apprehension and doubt as they could be, I hear the most when doing fieldwork. That some of the answers to these could themselves embody stigma might be a conundrum worth exploring. What is normal is probably to take care of the body, and what is natural might include maintaining that same body through, e.g., exercise or diet, or washing or clothing. And while for some of us these are easy-to-do tasks or activities, for others they might prove excruciating, awkward, out of reach, or beyond their capacity. Ultimately, which body is this that we are talking about? Elsewhere, I have quoted Margrit Shildrick's notion that the body is a fabrication, one that is "organised not according to an historically progressive discovery of the real, but as an always insecure and inconsistent artefact, which merely mimics material fixity" [84]. So to say, it is normal that the body, a living organism and a site in flux, changes, and eventually decays or declines. (Un)naturally, we do what we have to (and can) do to improve or maintain it.

The body is not only a material fabrication but also, and borrowing from Barbara Kruger's iconic piece of feminist art Untitled (Your body is a battleground), 1989, ${ }^{7}$ a battleground. Though the origin of this work is tied to a specific moment, the 1989's Women's March on Washington in support of reproductive freedom, it is also a timeless statement in that it declares the body in flux as the location of conflict. Going through bodily battles may be interpreted differently by different groups of people and through different points in history or across different geographies. Our bodily biographies, affected by the temporal and situated aspects of subjectivity and the permeability of the body, e.g., the aging body, are certainly influenced by the social, ecological, and historical perspectives available to us at the time we live or where we are in the world. Nonetheless, what persists is the body as disputed at sociocultural and political/moral levels, external effects and processes that pave the way to remove control from the internal events of the body, e.g., reproductive freedom as mentioned earlier. In other words, a conflict serves to perpetuate the inability of women and other marginalised groups to participate in society as equal citizens, as bodily battles shrouded in, e.g., access to healthcare, knowledge, or lack of autonomy, seemingly remind us how many of these battles are out of our control.

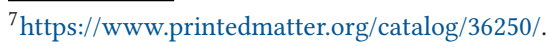


More so, changes to the body do not occur solely in material isolation or by means of external effects such as sociocultural values. The changing body is likely to have an impact on the identity constructed around it. While the body is a site of self-identity and a project to be worked upon, and, e.g., what we eat and the daily rituals through which we attend to the body are a medium of culture [65], disruptions that may pertain to the most personal and intimate sphere of interaction, such as infertility and menopause, or dysfunctions related to the aging body, e.g., revolving around bodily difficulties such as mobility and continence, to impact bodily esteem and to condition social engagement, might affect one's social self-worth. All of which, no matter where in the lifecourse or background, have an impact on quality of life.

It is all of the above that makes me ponder about the ways that the body has, thus far, been worked with in HCI. I wonder what designing for and with the body in HCI might mean to the majority of researchers in the field. It was not until the beginning of my $\mathrm{PhD}$ studies, started in 2012, that I started working in this field. My interests before this included designing with and for the body, and my approach was interdisciplinary and one that was driven mostly by artistic research. As a newcomer to HCI, it was interesting to me to see how, and perhaps by default, HCI had been treating and seeing the body as a niche research area to be dealt with mainly through focusing on ameliorating and remedying chronic to advanced health-related conditions or complications. This was clear from early-days' conversations with senior colleagues regarding possible research directions I could undertake, which included the topic of in/continence care, one that certainly would fit in an elderly care home context. Of course, I can see how this would have been fitting and in line with previous technology research or why this could be the first context of study someone might suggest, one in which the condition is likely tangible and easy to identify. Besides, and years later, in/continence care continues to be a largely underexplored but relevant area of research, a condition that nonetheless is associated with severe stigma and taboo, affects millions in Europe alone, and is critical to enabling mobility and ensure active aging as overall the world's older population is experiencing growth. That doing work on this topic is essential was never the question. The striking thing for me was instead the realisation that the field, which at the time I knew so little about, was so clearly interested in attending to making people's lives better through technology, but, yes, by primarily focusing on sustaining what was already "wrong" with them, other than addressing the broader context(s) that might lead to it. So, in wanting to do exactly that and to look at in/continence care throughout the lifespan, we set out to inquire about pelvic floor muscles. What is their relation to in/continence, e.g., can we see or touch them and in what context is that acceptable, where were we to start, and where did that leave us? And what tabooed and stigmatised bodily issues did our approach bring with it versus the supportive context of the care home, where statistics show us that the vast majority of elderly residents passively suffer from incontinence anyway? What is it then that we are left to work with, and how to make the work count towards the future of care and for it to be sustainable? What we attempted to do then and attempt to do now [ 8 , this issue] is to emphasise the body as a living organism and one that belongs to an ecosystem, e.g., whose physiology and morphology changes not only through the inevitability of time but also through the different events on someone's life. For example, it is popular knowledge that when travelling multiple time zones one's circadian rhythm or menstrual cycle could be affected, or as portrayed in public discourse that childbirth will lead to incontinence. Some of these bodily changes might be more temporary than others, and some requiring care in ways that help sustain everyday life for longer periods of time, as in the personal accounts of motherhood and parenting shared in Devendorf et al. [34, this issue], in which the authors reflect and relive their experiences in, e.g., fragility, whether through emotions such as joy or struggle and which, similarly to the aforementioned bodily changes, are personal and always in flux. 
From scientific fact to myth lies access to informed knowledge and understanding of the body as a living material that is permeable, temporal, and vulnerable. As an (part of) ecosystem, we live in and engage with it throughout the lifecourse, be it in biological, sociocultural, environmental, or political changes we experience. Those experiences, however, may vary depending on how and when we can or know how to care. And that I see as a possible strength in future HCI design research. What is acceptable to research or why should some topics be more acceptable than others, and who is or should be judging this? Why should we feel uneasy for doing such a line of work, in particular a body of work that wishes to improve people's quality of life through the design of technology, the very premises of HCI? This takes me back to the notion of subjugated knowledge, as discussed in $\mathrm{Ng}$ et al.'s [72, this issue]. In particular, that "is knowledge that is low status; it is naïve, uttered by a non-qualified speaker, failing to generalize. Falling short of counting as legitimate knowledge, it has no impact, no force; it is excluded from the operations of power; it is inefficacious." For technology to better support bodies, in particular those that are viewed as the "location of conflict," it should attend to change in productive ways. In other words, just as bodies are not construed as subject to the determinations of their biological entity, but also that of being socially inscribed and historically marked, so too the technologies that we design should be efficacious while legitimising knowledge that otherwise has been relegated to second place. This includes caring for the body and its functions at different stages in life, including in diversity and bodily experiences, while perceiving and addressing the reality of women and other marginalized groups' issues.

Madeline. What counts as legitimate knowledge is certainly a battleground that is returned to throughout this Special Issue. Our bodies are biologically continually in flux, and at the same time, the way we learn about our bodies and the ways it is treated change its nature. Several of the papers included in this Special Issue have examined this interplay between the body, society, culture, and technology. $\mathrm{Ng}$ and her collaborators [72, this issue] provide a good account of the educational issues that exist within Taiwan, but I think they credibly exist in many other countries as well, in terms of how the body works, what the parts are, and how these body parts should be treated. Similarly, in Kumar and collaborators' work [60, this issue], we see the shortage and avoidance of menstrual education as part of the formal Indian education system, and the influence it has on how menstruation is treated at an individual and social level. And, in Fox's contribution [43, this issue], we see how particular menstrual tracking technologies create certain kinds of bodies, and how individual users resist these models of how their bodies should work. Moving further, Kumar [60, this issue] and $\mathrm{Ng}$ [72, this issue] also provide accounts and case studies of how change can be made to happen at a social/cultural level. Kumar et al. [60, this issue] approach the problem of "women's health" through the lens of the "learning problem," focusing on the idea that multiple stakeholders impact on how information can be received and acted upon, and thus need to be accounted for in different ways as part of the design work. And, $\mathrm{Ng}$ et al. [72, this issue] show the role that design, in particular, can play in changing attitudes, what counts as legitimate and worthwhile: "In other words, the combined product development/political activist initiative produced knowledge, shifted the criteria of what counts as legitimate knowledge, and in so doing accrued political power that they used to enact sociopolitical change (and, incidentally, bring a product successfully to market)." On reading both submissions, I was reminded of Sara Ahmed's ideas of feminist willfulness [5]. Here, applied to design, it could be that the designed object is willful. It is the object that in "speaking up or speaking out" can upset the situation [4]. For a design to become willful, it should bring something into being, something that is unwanted or ignored. It forces attention to itself and the problem that it captures despite the audience's resistance to it.

For a long time, I have been involved with the deployment of FeedFinder [14, 31, 86]. It is a project that sticks to me despite the fact that all those who were involved in designing, developing, 
and studying it have moved on to new institutions, new jobs, and new projects. FeedFinder was designed to allow people who breastfeed and other supporters to share information about public breastfeeding experiences in the United Kingdom. And, over time, it became a source of data regarding the experience of public breastfeeding in the United Kingdom [87]. What we really tried to emphasise with this design was how whether a person chooses to breastfeed is not solely their individual decision, but actually very much informed and constrained by the sociopolitical context in which they live. Although we do not talk extensively about FeedFinder within our contribution to this Special Issue [8, this issue], as I read Ng et al.'s contribution to this Special Issue [72, this issue], I was once again reminded of this project and the challenges it raised. $\mathrm{Ng}$ and her colleagues highlight the work undertaken by an entrepreneur and a group of feminist activists in Taiwan to legitimate knowledge of vaginal wellness. If I take this same framing and apply it to the FeedFinder data, I question the extent to which the reviews and knowledge shared by breastfeeding people and their supporters ever became "legitimate knowledge." My view is these data/knowledge is still a subjugated knowledge despite being "evidenced" through the mobile application. In Simpson's exploration of health workers' use of the data captured through FeedFinder [86], the subjective experiences provided through FeedFinder were continually questioned by healthcare workers, and the concerns that were shared by users of the application were often undermined as not being relevant to increasing public breastfeeding. This, in turn, made it difficult to advocate for these experiences to be accounted for in local breastfeeding policy, or utilised as a means of measuring the baby friendliness of the city. Maybe we failed to make FeedFinder work adequately within the existing "system." In my mind, Ng and her colleagues both show how design can be made willful, and how it can come to matter as something with social and political consequences. And, in addition, $\mathrm{Ng}$ and her colleagues [72, this issue] and Kumar [60, this issue] and her colleagues illustrate the kind of work required to make social and political change from design.

I want to finish by briefly talking about time. What is striking about both of $\mathrm{Ng}$ et al.'s [72, this issue] and Kumar et al.'s [60, this issue] accounts is the element of time: the long amounts of time required, and the very "mundane" work necessary, to achieve any form of social and cultural change that can, in turn, change how the body is perceived and experienced. My own experience of this is that this kind of activist/research work is tiring, and mundane, and often really quite unpublishable. So, I suppose, what I am saying is that if as a coalition we are trying to undertake willful design that creates real social and political change, then we need to also consider our publication practices, our processes through which esteem is derived, and ask ourselves whether these are the conditions under which we are able to do this kind of work.

Shaowen. Like Teresa and Madeline, I am very pleased to see a diverse set of papers in this Special Issue united by their commitment to explore the "lived bodily experiences," focusing on the specificities of our material existence, mediated by the broader social, cultural, scientific, and political processes and narratives. The topic of changing bodies manifests differently in women's health in HCI, and I would like to follow up on a couple of threads that surfaced earlier: researching women's bodies in flux and the temporal dimension of women's health research.

In recent years, my collaborators, Jeffrey Bardzell, Amanda Lazar, and Norman Makoto Su, and I have been working on menopause wellbeing. Menopause refers to the point at which a woman has gone 12 months without a period. Most people experience menopause in their late 40s or early 50s, though some experience it much earlier or later [74]. Menopause is preceded by several years by perimenopause, when the ovaries decrease the production of certain hormones and individuals begin to experience physiological changes, including changes in menstrual frequency or flow, hot flashes, insomnia, night sweats, decreases in libido, weight gain, and mood changes. Menopause signifies the end of a woman's reproductive ability, after which she is considered to be postmenopause. 
In a study of a menopause subreddit that Amanda, Norman, Jeffrey, and I conducted [62], we attended to metaphors, diction, hyperbole, irony, and tropes in women's textual production with care, to understand their multiple and complex meanings. We did this in hopes of glimpsing that which cannot be directly observed: the ways that social structures shape experiences. Let me exemplify this. We often see paraphrases of what people say, often articulated in a scientific language: "Women report that...," "they experience unexpected periods," "they experience hot flashes," and/or "they experience physiological changes." But when one reads their words as they are written, whole new meanings emerge. Redditors wrote, "The last two floods were so heavy it felt like a cough"; "I had to wring out my shirt from sweat"; "body was hijacked by an alien."

We also saw metaphors of possession and transformation into some other kind of being dozens of times or more. But perhaps its plainest expression comes in the form of the question we saw more than all of the others in our data: "Am I normal?" This simple devastating question suggests that the woman in menopause is not even recognisable to herself. To my collaborators and I, the research on menopause suggests that menopause is far more than an individual medical or even health issue. Menopause has profound and life-altering experiential dimensions, issues of marginalisation and social injustice, and, not surprisingly, is increasingly mediated by sociotechnical systems. HCI research on menopause should work alongside, and not subordinate itself to, a health research agenda.

Another factor, which was brought up by Madeline earlier, is ways that women's health does not just exist in space, but it also exists in time. In the context of our work on menopause, we see many different kinds of time emerging from our data. There is nostalgic time, when individuals wish for what was-smooth skin, different bodies-and they want to go back. There is anticipatory time, when people imagine themselves the future, envisioning freedom from their period or turning into some sort of monster. Retrospective time has postmenopausal individuals reflecting on how they felt when they were experiencing what the younger generation is now going through. And there is even adventure time, when one can transform into a she-hulk and speak fearlessly for the first time in her life. The temporal facet of menopause's lived experience points to the need of shifting prioritising the ability to predict events from temporal patterns to designing artefacts that represent and share how women experience the temporal duality of menopause [21]. In designing menopause interventions, Jeffrey, Amanda, Norman, and I talked about taking a macroscopic viewpoint-events such as pregnancy, one's first period, and one's first hot flash are important for apps to work right, but also because of the way it affects how people make sense of their experiences. We wonder what would a period tracker look like that considers cycles not just as monthly, but taking place over one's life in phases (prepuberty, postpuberty, perimenopause, menopause).

Lone. This notion of time in research as well as in life is incredibly interesting on a conceptual and practical level, but also in connection to the general expectation in academia of producing research output often and rapidly. There is a perceived urgency in HCI research, which we see in, for instance, the "late breaking results" category at major conferences and which I often wish was called "unfinished thoughts so help me think them through" because that would emphasise how good thinking evolves with others. Also, making digital technology that expresses slowness or reflects on longer time frames seems counterintuitive to the quick responses and fast interactions that we are used to seeing. From the very beginning of HCI, focus has been on speed and accuracy (GOMS analysis, etc.), and while this is understandable in many settings, it also sets a particular tone for everything else. Shaowen is right that the human body has cycles that run in many tempi and many of them are slow or appear to us slowly. When the body is a permeable, temporal, and vulnerable living material as Teresa says, how does our working with it in design and HCI address the ways bodies make sense in the context they are in, we might ask? And how does the time frames of research affect this? Teresa further considers what it means to design with and for 
the body, and Madeline similarly addresses the interplay between the body, society, culture, and technology. Both could be connected to this thought of time, and I would like to end my part of the conversation by building on this to discuss future making and cultural conditions.

I have been interested in speculative or critical design for some time now. To me, one of the advantages of working specifically with design as a critical practice, in teaching as well as in research, is that it allows us to use the dramaturgical concept of suspending disbelief, often through time. Future making could be one word for this. Questions that we might ask in this practice are: "What if. .." something else had happened in the past? Or "what if. .." this particular aspect becomes the new norm in the future? Which designs exist and how are they embedded in life? This is not in order to solve particular problems and make calls to action for future developments, but in order to open a space for thinking critically and "deeply" about current situations, cultures, and norms. As Devendorf et al. write towards the end of their article, "the insights that can emerge as part of a speculative practice [...] are better oriented to highlighting places where our systems of design and evaluation fall short, rather than highlighting specific directions [...]" [34, this issue, p. 25]. Also Keyes et al. look to speculative practices when wanting to rethink the current situation in women's health research [57, this issue]. In thinking about future making as a thought process more than an ideation process, we emphasise how speculative interventions into present time can help us see the cultural context that we are too easily blind to. Attention to timelines shifts the perspective on the cultural blind spots, so to speak.

In a research management course I once took, we were reminded that "culture eats strategy for breakfast," which is a good metaphor describing how the most successful changes build on the existing fabric of a group, and we can extend this to HCI as such and to women's health in HCI specifically: Social and cultural factors have enormous impact on design, and this is why it is rarely a good idea to be ignorant of the culture that we work with. Understanding the finer nuances of a situation is important for many articles in this issue, for instance, Kumar et al., who write that, "The panic button was supposedly mandated in order to serve women's sense of safety [...]" $[60$, p. 12 , this issue], but, fundamentally, they argue, this was a useless although seemingly simple solution to a difficult problem. With Morozov we could call this "solutionism" [69], where designers hope that they do not have to understand the context that the problems are present in, but, instead, they simply make an app (for instance). This is not a new insight per se, and participatory design and Computer Supported Cooperative Work (CSCW), for instance, are explicitly based on trying to understand the context, but in this case, Kumar et al.'s example serves to show how addressing women's health is an intersectional matter to the core [60, this issue]. And how it matters to take seriously the cultural embedding of the question in the first place.

Shaowen mentioned earlier that design affects how people make sense of their experiences, and this is what many of the papers in this Special Issue revolve around. How do we, as people who do design but also who study design's effects, enable sensemaking through our practice with participants? And how do we ourselves make sense of our work? These two questions are connected, although sometimes the connections take time to form. In 2007, I coauthored a paper [58] about "embodied imagination," which described and reflected on a study in which Susan Kozel and I sought to rethink the design of devices for affective, networked communication, rr perhaps rather figure out ways of speculating through the embodied and lived lives of the participants instead of from a conceptual idea of how lives might be improved. We crafted soft bracelets for participants to wear over a few days, and we asked that since these were placebo objects, stand-ins for something that might be functional, what would that functionality be and when would it be nice to have? We were not searching for concrete ideas but for ways of thinking about the value of interpersonal connections. The experiment in itself was small and short, ran only for a couple of days, but it was part of a larger performative project on how we might think of wearables as something that 
can listen to our bodies and potentially foster a different kind of awareness and care for the self and others from the self-governance often associated with self-tracking. It was my first voyage into using the body as a material and a subject in my research, and in a poetic sense too: I started thinking about how digital technology can also be used to nurture people's sense of themselves and of others without it being for practical purposes or for laughs. On a very small scale at the time, I also realised that perhaps there were different ways of doing HCI, and that my arts and aesthetic humanities background might be useful somehow. Furthermore, this project obviously spurred many discussions about sexuality and how to be comfortable in one's own body as well as in society as a whole, and it was interesting to note how and when those conversations were easy to have: Projects within the arts were plenty, but it was much harder to see where HCI might take this, even if Shaowen's Feminist HCI work quickly became a beacon to me [22], as did the research on sex technologies $[19,56]$. And then, in 2016, Madeline and Teresa copublished two papers at CHI16 on women's health in HCI [7, 11]. It was so rare to see research in HCI circles that dealt with women's bodies in an unapologetic way, and even "dared" addressing sexuality and bodily awareness. An an instant fan of your work, I was happy to be coorganizing the CHI17 workshop [16] later on Hacking Women's Health.

Both experiences, 2007 and 2016, reminded me that one should never underestimate the power of finding people who care about the same issues as yourself. "Am I normal?" is how Shaowen summarises her participants' concerns about their menopausal situation, and if I may pull that question out of its context for a minute, I think it is a useful question to ask here, both with regard to how the body materialises in design and HCI research and with regard to how we as researchers make space for each other and for others; how we build a community that shares affinities even if we do not agree on everything. Part of my journey is described above, and it would be my hope that this Special Issue can have a bit of that effect on those who read the contributions and realise that this might be their people.

In rounding up my part of the conversation, I am again reminded of two things: first, the strength expressed in the articles of this issue, where much of what has been written about has taken courage and a particular kind of stamina to do, for instance, expressed through the explicit vulnerability in Devendorf et al. [34, this issue]; and, second, Puig de la Bellacasa's extension of Latour's worry (that research needs to find a way in a world marked by fact resisting politics) when she articulates how "matters of care" might work as a useful metaphor in order to rethink how research and academic thinking can matter [77]. If we combine the courage to be vulnerable, the ability to think through the margins, and the ambition to care, perhaps then will we find a way to consolidate women's health in HCI as a critical endeavour that might also change the bodies of research in HCI.

\section{THE RESILIENCE OF FRAGILE SUBJECTS}

Neither one of us, however, is able to claim that what we have done (our choice of subjects as well as our manner of writing about them), we have done-or dared to do-because we were women. We worked this way because we imagined that philosophy should be done this way as well, because this is what we hoped for it to be: it was in doing philosophy this way that we showed that it was possible. At no moment did we envisage that doing philosophy this way could designate us as "women philosophers." [89, p. 15]

When we started working on women's health in HCI, models of how to do this kind of sensitive work were not available. Of course, there has been prior research on how to tackle sensitive topics such as human sexuality [23, 56], among others, but an activist approach to women's health HCI 
was few and far between. So, we started from our own embodied experiences and our own work went from there. Following Stengers and Despret [89], we did it not because we are women but because it was our hope that this is what HCI as such could become better at: working to address issues from what was considered "the margins" [22]. In positioning us at what was (and still often is) considered the margins, we as researchers were (and still are) ascribed to an activist agenda. While we do not mind per se, because in many ways it is activist work too, it seems that those that are open about their standpoint and positionality are more prone to critique than those who are not. The marked position is visible, and the unmarked is not. Research comes from somewhere and it has an intentionality; women's health research is very open about that, whereas many other types of research is less so.

The notion of unmarked positions is important because it matters to the research done in women's health in HCI. It matters everywhere else too, but it is rarely being noticed. In May 2019, UNESCO examined the gendering of AI technology as part of a report that focused on the gender divide in technical education. ${ }^{8}$ With a title taken from a (now no longer active) response from Apple's Siri service "I'd blush if I could"-a possible response to a user giving Siri a "cat call"-the report concluded that virtual assistants are gender biased and that this is highly problematic for at least two reasons: First, it reflects, reinforces, and spreads gender bias, and, second this increased gendering is due to a lack of diversity in the developer teams. We do not believe that this part of the tech industry is terribly different from other parts (inclusive research), and we hope that perhaps the critical women's health research in HCI will enable more research to understand how gender issues matter in research and in deployments of digital technologies. No research in HCI should be blind to the implicit silencing of voices and perspectives that research can foster, and a feminist response would be to position oneself with an eye for intersectional aspects. All of the articles in this Special Issue do this careful work in their own way.

A feminist way of working is to seek to create a community that fosters collaborations and allows for new things to come forward, as imperfect as they are. In this sense, we believe that all good feminist (health) activist work continuously reflects on existing and previous work and knows that moving forward is also a matter of understanding the effects of our own work both on the participants in our studies and on the scholarly thinking that we all make, both as a collective/community and as individual researchers. It takes time, courage, effort, and care to revisit the earlier agendas and to recognise blind spots in our own thinking that needs to be addressed. And it takes time, courage, effort, and care to work from a position of multiple voices that may never agree but still benefit from sticking together. We believe that the premise of feminist scholarship (applying to women's health research in HCI) is to bring dissensus into productive use, to include multiple voices and standpoints in order to understand the effect of perspectives and positions, as well as to bring forward how context always frames and conditions research.

The new politics of feminist health research in $\mathrm{HCI}$ also requires that we do not just preach but also practice as part of our lifeworld of being feminist scholars and also vulnerable human beingsrecognising and embracing the diversity in agendas of problematising and reenvisioning women's health research and committing to call out and intervene upon factors that produce inequalities and injustices in women's health. We wish for a broader epistemic, societal, and social justice uptake of this work beyond women's health research. To us (and channelling Tasha Dubriwny [37]), doing feminist health research in HCI means attending to the politics of bodily knowledge, bodily self-determination, as well as the structural and institutional complexity of biomedicine, which normalises our bodies in clinical, scientific, and cultural practices. But it also means attending to our selves and how we relate to one another as researchers. We need pluralistic and generous

\footnotetext{
${ }^{8}$ https://unesdoc.unesco.org/ark:/48223/pf0000367416.
} 
engagements with the work of diverse scholars in this space-including those who do not share with us the same epistemic positioning, methodological orientation, or linguistic practice-so that we may recognise each other as fellow travellers and that we are in this together.

\section{ACKNOWLEDGMENTS}

We would like to acknowledge the following authors who have been spearheading the research in women's health HCI: [14, 24, 44, 45, 59, 70, 75, 76, 95, 102], and the many more who we have not cited here. In recent years, this work has broadened to explore and respond to issues such as domestic violence [30], abortion [66], pregnancy loss [12, 13], menstruation [20, 27, 28, 38, 41, $50,92,101]$, intimate anatomical awareness [10, 11], fertility management [32, 52, 83], continence care [7], menopause [21, 51, 62, 99], voice training for trans-women [2], gender stereotypes in voice assistants [94]), and re-imagine existing practices and technologies [16, 35]. We would also like to acknowledge Jeffrey Bardzell, Rob Comber, Kia Höök, the reviewers, and all of our interlocutors for their intellectual contribution, support, and encouragement in curating this special issue.

\section{REFERENCES}

[1] Alex Ahmed and Teresa Almeida. 2017. Human to human. XRDS: Crossroads: The ACM Magazine for Students 24, 2 (Dec. 2017), 7-9. DOI : https://doi.org/10.1145/3155130

[2] Alex A. Ahmed. 2018. Trans competent interaction design: A qualitative study on voice, identity, and technology. Interacting with Computers 30, 1 (Jan. 2018), 53-71. DOI : https://doi.org/10.1093/iwc/iwx018

[3] Alex A. Ahmed, Teresa Almeida, Judeth Oden Choi, Jon Pincus, and Kelly Ireland. 2018. What's at issue: Sex, stigma, and politics in acm publishing. In Extended Abstracts of the 2018 CHI Conference on Human Factors in Computing Systems. ACM, 1-10. DOI : https://doi.org/10.1145/3170427.3188400

[4] Sara Ahmed. 2010. Feminist killjoys (and other willful subjects). The Scholar and Feminist Online 8, 3 (2010), 1-8.

[5] Sara Ahmed. 2017. Living a Feminist Life. Duke University Press, Durham, NC.

[6] Btihaj Ajana. 2017. Digital health and the biopolitics of the quantified self. DIGITAL HEALTH 3 (Jan. 2017), 1-18. DOI : https://doi.org/10.1177/2055207616689509

[7] Teresa Almeida, Rob Comber, and Madeline Balaam. 2016. HCI and intimate care as an agenda for change in women's health. In Proceedings of the 2016 CHI Conference on Human Factors in Computing Systems. ACM, 2599-2611. DOI : https://doi.org/10.1145/2858036.2858187

[8] Teresa Almeida, Rob Comber, and Madeline Balaam. 2020. Woman-centered design through humanity, activism, and inclusion. ACM Transactions on Computer-Human Interaction 27, 4, Article 27 (2020). DOI : https://doi.org/10.1145/ 3397176

[9] Teresa Almeida, Rob Comber, Patrick Olivier, and Madeline Balaam. 2014. Intimate care: Exploring etextiles for teaching female pelvic fitness. In Proceedings of the 2014 Companion Publication on Designing Interactive Systems (DIS Companion'14). ACM, 5-8. DOI: https://doi.org/10.1145/2598784.2602768

[10] Teresa Almeida, Rob Comber, Gavin Wood, Dean Saraf, and Madeline Balaam. 2016. On looking at the vagina through labella. In Proceedings of the 2016 CHI Conference on Human Factors in Computing Systems. ACM, 18101821. DOI : https://doi.org/10.1145/2858036.2858119

[11] Teresa Almeida, Gavin Wood, Rob Comber, and Madeline Balaam. 2016. Interactivity: Looking at the vagina through labella. In Proceedings of the 2016 CHI Conference Extended Abstracts on Human Factors in Computing Systems (CHI EA'16). ACM, 3635-3638. DOI : https://doi.org/10.1145/2851581.2890261

[12] Mona Y. Alqassim, K. Cassie Kresnye, Katie A. Siek, and Maria K. Wolters. 2019. Facebook for support versus facebook for research: The case of miscarriage. In Extended Abstracts of the 2019 CHI Conference on Human Factors in Computing Systems. ACM, 1-6. DOI : https://doi.org/10.1145/3290607.3312772

[13] Nazanin Andalibi and Andrea Forte. 2018. Announcing pregnancy loss on facebook: A decision-making framework for stigmatized disclosures on identified social network sites. In Proceedings of the $2018 \mathrm{CHI}$ Conference on Human Factors in Computing Systems (CHI'18). ACM, 1-14. DOI : https://doi.org/10.1145/3173574.3173732

[14] Madeline Balaam, Rob Comber, Ed Jenkins, Selina Sutton, and Andrew Garbett. 2015. FeedFinder: A locationmapping mobile application for breastfeeding women. In Proceedings of the 33rd Annual ACM Conference on Human Factors in Computing Systems (CHI'15). ACM, 1709-1718. DOI : https://doi.org/10.1145/2702123.2702328

[15] Madeline Balaam and Lone Koefoed Hansen. 2017. Women's health @ CHI. Interactions 25, 1 (Dec. 2017), 6-7. DOI : https://doi.org/10.1145/3169797 
[16] Madeline Balaam, Lone Koefoed Hansen, Catherine D’Ignazio, Emma Simpson, Teresa Almeida, Stacey Kuznetsov, Mike Catt, and Marie L. J. Søndergaard. 2017. Hacking women's health. In Proceedings of the 2017 CHI Conference Extended Abstracts on Human Factors in Computing Systems (CHI EA'17). ACM, 476-483. DOI : https://doi.org/10. $1145 / 3027063.3027085$

[17] Madeline Balaam, Judy Robertson, Geraldine Fitzpatrick, Rebecca Say, Gillian Hayes, Melissa Mazmanian, and Belinda Parmar. 2013. Motherhood and HCI. In CHI'13 Extended Abstracts on Human Factors in Computing Systems on (CHI EA'13). ACM, 3215. DOI : https://doi.org/10.1145/2468356.2479650

[18] Karen Michelle Barad. 2007. Meeting the Universe Halfway: Quantum Physics and the Entanglement of Matter and Meaning. Duke University Press, Durham, NC.

[19] Jeffrey Bardzell and Shaowen Bardzell. 2011. Pleasure is your birthright: Digitally enabled designer sex toys as a case of third-wave HCI. In Proceedings of the 2011 Annual Conference on Human Factors in Computing Systems (CHI'11). ACM, 257. DOI : https://doi.org/10.1145/1978942.1978979

[20] Jeffrey Bardzell, Shaowen Bardzell, and Lone Koefoed Hansen. 2015. Immodest proposals: Research through design and knowledge. In Proceedings of the 33rd Annual ACM Conference on Human Factors in Computing Systems (CHI'15). ACM, 2093-2102. DOI : https://doi.org/10.1145/2702123.2702400

[21] Jeffrey Bardzell, Shaowen Bardzell, Amanda Lazar, and Norman Makoto Su. 2019. (Re-)framing menopause experiences for hci and design. In Proceedings of the 2019 CHI Conference on Human Factors in Computing Systems (CHI'19). ACM, 1-13. DOI : https://doi.org/10.1145/3290605.3300345

[22] Shaowen Bardzell. 2010. Feminist HCI: Taking stock and outlining an agenda for design. In Proceedings of the 28th International Conference on Human Factors in Computing Systems (CHI'10). ACM, 1301. DOI : https://doi.org/10.1145/ 1753326.1753521

[23] Shaowen Bardzell and Jeffrey Bardzell. 2011. Towards a feminist HCI methodology: Social science, feminism, and HCI. In Proceedings of the 2011 Annual Conference on Human Factors in Computing Systems (CHI'11). ACM, 675. DOI : https://doi.org/10.1145/1978942.1979041

[24] Marguerite Barry, Kevin Doherty, Jose Marcano Belisario, Josip Car, Cecily Morrison, and Gavin Doherty. 2017. mHealth for maternal mental health: Everyday wisdom in ethical design. In Proceedings of the 2017 CHI Conference on Human Factors in Computing Systems. ACM, 2708-2756. DOI : https://doi.org/10.1145/3025453.3025918

[25] Lisa Bowleg. 2012. The problem with the phrase women and minorities: Intersectionality-an important theoretical framework for public health. American fournal of Public Health 102, 7 (Jul. 2012), 1267-1273. DOI : https://doi.org/10. 2105/AJPH.2012.300750

[26] Virginia Braun. 1999. Breaking a taboo? Talking (and laughing) about the vagina. Feminism \& Psychology 9, 3 (Aug. 1999), 367-372. DOI : https://doi.org/10.1177/0959353599009003014

[27] Nadia Campo Woytuk, Linette Nilsson, and Mingxing Liu. 2019. Your period rules: Design implications for periodpositive technologies. In Extended Abstracts of the 2019 CHI Conference on Human Factors in Computing Systems. ACM, 1-6. DOI : https://doi.org/10.1145/3290607.3312888

[28] Nadia Campo Woytuk, Marie Louise Juul Søndergaard, Marianela Ciolfi Felice, and Madeline Balaam. 2020. Touching and being in touch with the menstruating body. In Proceedings of the 2020 CHI Conference on Human Factors in Computing Systems. ACM, 1-14. DOI : https://doi.org/10.1145/3313831.3376471

[29] Zoanne Clack. 2020. Women's Health Concerns Are Dismissed More, Studied Less. National Geographic (Jan. 2020). Retrieved from www.nationalgeographic.com.au.

[30] Rachel Clarke, Peter Wright, Madeline Balaam, and John McCarthy. 2013. Digital portraits: Photo-sharing after domestic violence. In Proceedings of the SIGCHI Conference on Human Factors in Computing Systems (CHI'13). ACM, 2517. DOI : https://doi.org/10.1145/2470654.2481348

[31] Shauna Julia Concannon, Madeline Balaam, Emma Simpson, and Rob Comber. 2018. Applying computational analysis to textual data from the wild: A feminist perspective. In Proceedings of the 2018 CHI Conference on Human Factors in Computing Systems (CHI'18). ACM, 1-13. DOI : https://doi.org/10.1145/3173574.3173800

[32] Mayara Costa Figueiredo, Clara Caldeira, Elizabeth Victoria Eikey, Melissa Mazmanian, and Yunan Chen. 2018. Engaging with health data: The interplay between self-tracking activities and emotions in fertility struggles. Proceedings of the ACM on Human-Computer Interaction 2, CSCW (Nov. 2018), 1-20. DOI : https://doi.org/10.1145/3274309

[33] Jonathan Crary. 2014. 24/7: Late Capitalism and the Ends of Sleep. Verso, London.

[34] Laura Devendorf, Kristina Andersen, and Aisling Kelliher. 2020. The fundamental uncertainties of mothering: Honoring endurance, struggle, and contradiction. ACM Transactions on Computer-Human Interaction 27, 4, Article 26 (2020). DOI : https://doi.org/10.1145/3397177

[35] Catherine D’Ignazio, Alexis Hope, Becky Michelson, Robyn Churchill, and Ethan Zuckerman. 2016. A feminist HCI approach to designing postpartum technologies: "When I first saw a breast pump I was wondering if it was a joke." In Proceedings of the 2016 CHI Conference on Human Factors in Computing Systems. ACM, 2612-2622. DOI: https:// doi.org/10.1145/2858036.2858460 
[36] Catherine D’Ignazio and Lauren F. Klein. 2020. Data Feminism. MIT Press, Cambridge, MA.

[37] Tasha N. Dubriwny. 2013. The Vulnerable Empowered Woman: Feminism, Postfeminism, and Women's Health. Rutgers University Press, New Brunswick, NJ.

[38] Daniel A. Epstein, Nicole B. Lee, Jennifer H. Kang, Elena Agapie, Jessica Schroeder, Laura R. Pina, James Fogarty, Julie A. Kientz, and Sean Munson. 2017. Examining menstrual tracking to inform the design of personal informatics tools. In Proceedings of the 2017 CHI Conference on Human Factors in Computing Systems. ACM, 6876-6888. DOI : https://doi.org/10.1145/3025453.3025635

[39] Ashley Fetters. 2018. The Doctor Doesn't Listen to Her. But the Media Is Starting To.Retrieved from https://www. theatlantic.com/family/archive/2018/08/womens-health-care-gaslighting/567149/.

[40] Hanne Fokdal. 1989. Kvinde, Kend Din Krop: En håndbog. Tiderne Skifter, Copenhagen.

[41] Sarah Fox, Noura Howell, Richmond Wong, and Franchesca Spektor. 2019. Vivewell: Speculating near-future menstrual tracking through current data practices. In Proceedings of the 2019 on Designing Interactive Systems Conference. ACM, 541-552. DOI : https://doi.org/10.1145/3322276.3323695

[42] Sarah Fox, Amanda Menking, Stephanie Steinhardt, Anna Lauren Hoffmann, and Shaowen Bardzell. 2017. Imagining intersectional futures: Feminist approaches in CSCW. In Companion of the 2017 ACM Conference on Computer Supported Cooperative Work and Social Computing (CSCW'17 Companion). ACM, 387-393. DOI: https://doi.org/10. 1145/3022198.3022665

[43] Sarah E. Fox, Amanda Menking, Jordan Eschler, and Uba Backonja. 2020. Multiples over models. ACM Transactions on Computer-Human Interaction 27, 4, Article 22 (2020). DOI : https://doi.org/10.1145/3397178

[44] Lorna Gibson and Vicki L. Hanson. 2013. Digital motherhood: How does technology help new mothers?. In Proceedings of the SIGCHI Conference on Human Factors in Computing Systems (CHI'13). ACM, 313. DOI : https://doi.org/10. 1145/2470654.2470700

[45] Xinning Gui, Yu Chen, Yubo Kou, Katie Pine, and Yunan Chen. 2017. Investigating support seeking from peers for pregnancy in online health communities. Proceedings of the ACM on Human-Computer Interaction 1, CSCW (Dec. 2017), 1-19. DOI : https://doi.org/10.1145/3134685

[46] Donna Haraway. 2016. Staying with the Trouble: Making Kin in the Chthulucene. Duke University Press.

[47] Donna Haraway. 1991. A cyborg manifesto: Science, technology, and socialist-feminism in the late twentieth century. In Simians, Cyborgs and Women: The Reinvention of Nature. Routledge, New York, 149-181.

[48] Patricia Hill Collins. 2009. Black Feminist Thought: Knowledge, Consciousness, and the Politics of Empowerment (2nd ed.). Routledge, New York, NY.

[49] Diane E. Hoffmann and Anita J. Tarzian. 2001. The girl who cried pain: A bias against women in the treatment of pain. The Journal of Law, Medicine \& Ethics 28, 4_Suppl (Mar. 2001), 13-27. DOI : https://doi.org/10.1111/j.1748-720X. 2001.tb00037.x

[50] Sarah Homewood. 2018. Designing for the changing body: A feminist exploration of self-tracking technologies. In Extended Abstracts of the 2018 CHI Conference on Human Factors in Computing Systems. ACM, 1-4. DOI: https:// doi.org/10.1145/3170427.3173031

[51] Sarah Homewood. 2019. Inaction as a design decision: Reflections on not designing self-tracking tools for menopause. In Extended Abstracts of the 2019 CHI Conference on Human Factors in Computing Systems. ACM, 112. DOI : https://doi.org/10.1145/3290607.3310430

[52] Sarah Homewood, Harvey Bewley, and Laurens Boer. 2019. Ovum: Designing for fertility tracking as a shared and domestic experience. In Proceedings of the 2019 on Designing Interactive Systems Conference. ACM, 553-565. DOI : https://doi.org/10.1145/3322276.3323692

[53] Kristina Höök. 2018. Designing with the Body: Somaesthetic Interaction Design. MIT Press, Cambridge, MA.

[54] Kristina Höök. 2019. The day I am a researcher: Not my gender. Interactions 26, 6 (Oct. 2019), 20-21. DOI : https:// doi.org/10.1145/3365217

[55] Lisa C. Ikemoto. 2006. In the shadow of race: Women of color in health disparities policy. U.C. Davis Law Review 39 , 3 (2006).

[56] Gopinaath Kannabiran, Jeffrey Bardzell, and Shaowen Bardzell. 2011. How HCI talks about sexuality: Discursive strategies, blind spots, and opportunities for future research. In Proceedings of the 2011 Annual Conference on Human Factors in Computing Systems (CHI'11). ACM, 695. DOI : https://doi.org/10.1145/1978942.1979043

[57] Os Keyes, Burren Peil, Rua M. Williams, and Katta Speil. 2020. Reimagining (women's) health: HCI, gender and essentialised embodiment. ACM Transactions on Computer-Human Interaction 27, 4, Article 25 (2020), 42 pages. DOI : https://doi.org/10.1145/3404218

[58] Lone Koefoed Hansen and Susan Kozel. 2007. Embodied imagination: A hybrid method of designing for intimacy. Digital Creativity 18, 4 (Dec. 2007), 207-220. DOI : https://doi.org/10.1080/14626260701743200

[59] Neha Kumar and Richard J. Anderson. 2015. Mobile phones for maternal health in rural india. In Proceedings of the 33rd Annual ACM Conference on Human Factors in Computing Systems (CHI'15). ACM, 427-436. DOI : https://doi.org/ 10.1145/2702123.2702258 
[60] Neha Kumar, Naveena Karusala, Azra Ismail, and Anupriya Tuli. 2020. Taking the long, intersectional, and holistic view to women's wellbeing. ACM Transactions on Computer-Human Interaction 27, 4, Article 23 (2020), 32 pages. DOI : https://doi.org/10.1145/3397159

[61] Bruno Latour. 2004. Why has critique run out of steam? From matters of fact to matters of concern. Critical Inquiry 30, 2 (2004), 225-248. DOI : https://doi.org/10.1086/421123 arXiv:https://doi.org/10.1086/421123

[62] Amanda Lazar, Norman Makoto Su, Jeffrey Bardzell, and Shaowen Bardzell. 2019. Parting the red sea: Sociotechnical systems and lived experiences of menopause. In Proceedings of the 2019 CHI Conference on Human Factors in Computing Systems (CHI'19). ACM, 1-16. DOI : https://doi.org/10.1145/3290605.3300710

[63] Ursula K. Le Guin. 1989. Dancing at the Edge of the World: Thoughts on Words, Women, Places. Grove Press, New York, NY.

[64] Audre Lorde. 1984. Sister Outsider: Essays and Speeches. Crossing Press, Berkeley, CA.

[65] Deborah Lupton. 1994. Medicine as Culture: Illness, Disease and the Body (1st ed.). SAGE Publications Ltd, London. DOI : https://doi.org/10.4135/9781446254530

[66] Lydia Michie, Madeline Balaam, John McCarthy, Timur Osadchiy, and Kellie Morrissey. 2018. From her story, to our story: Digital storytelling as public engagement around abortion rights advocacy in Ireland. In Proceedings of the 2018 CHI Conference on Human Factors in Computing Systems (CHI'18). ACM, 1-15. DOI : https://doi.org/10.1145/ 3173574.3173931

[67] Annemarie Mol. 2002. The Body Multiple: Ontology in Medical Practice. Duke University Press, Durham, NC.

[68] Annemarie Mol. 2008. The Logic of Care. Routledge. DOI : https://doi.org/10.4324/9780203927076

[69] Evgeny Morozov. 2013. To Save Everything, Click Here: The Folly of Technological Solutionism (1st ed.). PublicAffairs, New York, NY.

[70] Maryam Mustafa, Amna Batool, Beenish Fatima, Fareeda Nawaz, Kentaro Toyama, and Agha Ali Raza. 2020. Patriarchy, maternal health and spiritual healing: Designing maternal health interventions in pakistan. In Proceedings of the 2020 CHI Conference on Human Factors in Computing Systems. ACM, 1-13. DOI : https://doi.org/10.1145/3313831. 3376294

[71] Lisa Nakamura. 2002. Cybertypes: Race, Ethnicity, and Identity on the Internet. Routledge, New York, NY.

[72] Sarah Ng, Shaowen Bardzell, and Jeffrey Bardzell. 2020. The menstruating entrepreneur: Kickstarting a new politics of women's health. ACM Transactions on Computer-Human Interaction 27, 4, Article 21 (2020), 25 pages. DOI : https: //doi.org/10.1145/3397158

[73] National Institutes of Health. 2014. Women of Color Health Data Book (4th ed.). National Institutes of Health.

[74] S. Palacios, V. W. Henderson, N. Siseles, D. Tan, and P. Villaseca. 2010. Age of menopause and impact of climacteric symptoms by geographical region. Climacteric 13, 5 (Oct. 2010), 419-428. DOI : https://doi.org/10.3109/13697137.2010. 507886

[75] Tamara Peyton, Erika Poole, Madhu Reddy, Jennifer Kraschnewski, and Cynthia Chuang. 2014. "Every pregnancy is different": Designing mHealth for the pregnancy ecology. In Proceedings of the 2014 Conference on Designing Interactive Systems (DIS'14). ACM, 577-586. DOI : https://doi.org/10.1145/2598510.2598572

[76] Annu Sible Prabhakar, Nikki Newhouse, Emma Simpson, Christine Wanjiru Mburu, Nova Ahmed, and Yunan Chen. 2019. MatHealthXB: Designing across borders for global maternal health. In Extended Abstracts of the 2019 CHI Conference on Human Factors in Computing Systems. ACM, 1-4. DOI : https://doi.org/10.1145/3290607.3311755

[77] María Puig de la Bellacasa. 2017. Matters of Care: Speculative Ethics in More Than Human Worlds. University of Minnesota Press, Minneapolis, MN.

[78] Catherine Kohler Riessman. 1983. Women and medicalization: A new perspective.Social Policy 14, 1 (1983), 3-18.

[79] John Rooksby, Mattias Rost, Alistair Morrison, and Matthew Chalmers Chalmers. 2014. Personal tracking as lived informatics. In Proceedings of the 32nd Annual ACM Conference on Human Factors in Computing Systems (CHI'14). ACM, 1163-1172. DOI: https://doi.org/10.1145/2556288.2557039

[80] Sara Ruddick. 1995. Maternal Thinking: Toward a Politics of Peace; with a New Preface. Beacon Press, Boston, MA.

[81] Chela Sandoval. 1991. U.S. third world feminism: The theory and method of oppositional consciousness in the postmodern world. Genders 10 (Mar. 1991), 1-24. DOI : https://doi.org/10.5555/gen.1991.10.1

[82] Ari Schlesinger, W. Keith Edwards, and Rebecca E. Grinter. 2017. Intersectional HCI: Engaging identity through gender, race, and class. In Proceedings of the 2017 CHI Conference on Human Factors in Computing Systems. ACM, 5412-5427. DOI : https://doi.org/10.1145/3025453.3025766

[83] Hanna Schneider, Julia Wayrauther, Mariam Hassib, and Andreas Butz. 2019. Communicating uncertainty in fertility prognosis. In Proceedings of the 2019 CHI Conference on Human Factors in Computing Systems (CHI'19). ACM, 1-11. DOI : https://doi.org/10.1145/3290605.3300391

[84] Margrit Shildrick. 1997. Leaky Bodies and Boundaries: Feminism, Postmodernism and (Bio)Ethics. Routledge, London, UK.

[85] Jael Miriam Silliman (Ed.). 2004. Undivided Rights: Women of Color Organize for Reproductive fustice. South End Press, Cambridge, MA. 
[86] Emma Simpson, Rob Comber, Andrew Garbett, Ed Ian Jenkins, and Madeline Balaam. 2017. Experiences of delivering a public health data service. In Proceedings of the 2017 CHI Conference on Human Factors in Computing Systems. ACM, 6171-6183. DOI : https://doi.org/10.1145/3025453.3025881

[87] Emma Simpson, Andrew Garbett, Rob Comber, and Madeline Balaam. 2016. Factors important for women who breastfeed in public: A content analysis of review data from FeedFinder. BMJ Open 6, 10 (Oct. 2016), e011762. DOI : https://doi.org/10.1136/bmjopen-2016-011762

[88] Charlotte Wessel Skovlund, Lina Steinrud Mørch, Lars Vedel Kessing, and Øjvind Lidegaard. 2016. Association of hormonal contraception with depression. JAMA Psychiatry 73, 11 (Nov. 2016), 1154. DOI : https://doi.org/10.1001/ jamapsychiatry.2016.2387

[89] Isabelle Stengers and Vinciane Despret. 2014. Women Who Make a Fuss: : The Unfaithful Daughters of Virginia Woolf (trans. April Knutson). Univocal Publishing, Minneapolis, MN.

[90] Anna Ståhl, Martin Jonsson, Johanna Mercurio, Anna Karlsson, Kristina Höök, and Eva-Carin Banka Johnson. 2016. The soma mat and breathing light. In Proceedings of the 2016 CHI Conference Extended Abstracts on Human Factors in Computing Systems (CHI EA'16). ACM, 305-308. DOI : https://doi.org/10.1145/2851581.2889464

[91] Marie Louise Juul Søndergaard. 2020. Troubling design: A design program for designing with women's health. ACM Transactions on Computer-Human Interaction 27, 4, Article 24 (2020), 36 pages. DOI : https://doi.org/10.1145/3397199

[92] Marie Louise Juul Søndergaard and Lone Koefoed Hansen. 2016. PeriodShare: A bloody design fiction. In Proceedings of the 9th Nordic Conference on Human-Computer Interaction (NordiCHI'16). ACM1-6. DOI : https://doi.org/10.1145/ 2971485.2996748

[93] Marie Louise Juul Søndergaard and Lone Koefoed Hansen. 2017. "It’s not that It Will Kill me" I: Living with electromagnetic hypersensitivity. Nordes 7, 1 (2017). Retrieved from https://archive.nordes.org/index.php/n13/article/view/ 558 Number: 1.

[94] Marie Louise Juul Søndergaard and Lone Koefoed Hansen. 2018. Intimate futures: Staying with the trouble of digital personal assistants through design fiction. In Proceedings of the 2018 on Designing Interactive Systems Conference 2018 (DIS'18). ACM, 869-880. DOI : https://doi.org/10.1145/3196709.3196766

[95] Reem Talhouk, Sandra Mesmar, Anja Thieme, Madeline Balaam, Patrick Olivier, Chaza Akik, and Hala Ghattas. 2016. Syrian refugees and digital health in lebanon: Opportunities for improving antenatal health. In Proceedings of the 2016 CHI Conference on Human Factors in Computing Systems. ACM, 331-342. DOI : https://doi.org/10.1145/ 2858036.2858331

[96] Reem Talhouk, Kellie Morrissey, Sarah Fox, Nadia Pantidi, Emma Simpson, Lydia Emma Michie, and Madeline Balaam. 2018. Human computer interaction \& health activism. In Extended Abstracts of the 2018 CHI Conference on Human Factors in Computing Systems. ACM, 1-4. DOI: https://doi.org/10.1145/3170427.3185369

[97] Sri Harsha Tella and J. Christopher Gallagher. 2014. Prevention and treatment of postmenopausal osteoporosis. The Journal of Steroid Biochemistry and Molecular Biology 142 (2014), 155-170. DOI : https://doi.org/10.1016/j.jsbmb.2013. 09.008

[98] Andrew Thomas. 2020. Exercise Changes the Way Our Bodies Work at a Molecular Level. Retrieved from http:// theconversation.com/exercise-changes-the-way-our-bodies-work-at-a-molecular-level-73335.

[99] Amaury Trujillo and Maria Claudia Buzzi. 2018. Towards a fuzzy rule-based systems approach for adaptive interventions in menopause self-care. In Adjunct Publication of the 26th Conference on User Modeling, Adaptation and Personalization. ACM, 53-56. DOI : https://doi.org/10.1145/3213586.3226193

[100] Nancy Tuana. 2006. The speculum of ignorance: The women's health movement and epistemologies of ignorance. Hypatia 21, 3 (2006), 1-19. DOI : https://doi.org/10.1111/j.1527-2001.2006.tb01110.x

[101] Anupriya Tuli, Shaan Chopra, Pushpendra Singh, and Neha Kumar. 2020. Menstrual (Im)mobilities and safe spaces. In Proceedings of the 2020 CHI Conference on Human Factors in Computing Systems. ACM, 1-15. DOI : https://doi.org/ $10.1145 / 3313831.3376653$

[102] Chelsea-Joy Wardle, Mitchell Green, Christine Wanjiru Mburu, and Melissa Densmore. 2018. Exploring co-design with breastfeeding mothers. In Proceedings of the 2018 CHI Conference on Human Factors in Computing Systems (CHI'18). ACM, 1-12. DOI : https://doi.org/10.1145/3173574.3174056

[103] Matthew Wood, Gavin Wood, and Madeline Balaam. 2017. Sex talk: Designing for sexual health with adolescents. In Proceedings of the 2017 Conference on Interaction Design and Children. ACM, 137-147. DOI : https://doi.org/10.1145/ 3078072.3079747

[104] Cecilia Åsberg and Lynda Birke. 2010. Biology is a feminist issue: Interview with Lynda Birke. European fournal of Women's Studies 17, 4 (Nov. 2010), 413-423. DOI : https://doi.org/10.1177/1350506810377696 